\title{
Improved Characterization of the Solution Kinetics and Thermodynamics of Biotin, Biocytin and HABA Binding to Avidin and Streptavidin.
}

Roberto F. Delgadillo, ${ }^{a, b,{ }^{\dagger}, *}$ Timothy C. Mueser, ${ }^{c}$ Kathia Zaleta-Rivera, ${ }^{d}$ Katie A. Carnes, ${ }^{e}$ José González-Valdez, ${ }^{b}$ and Lawrence J. Parkhurst ${ }^{a^{*}}$

${ }^{\text {a }}$ Department of Chemistry, University of Nebraska - Lincoln, Lincoln, NE 68588-0304, USA

b Tecnologico de Monterrey, School of Engineering and Sciences, Av. Eugenio Garza Sada 2501 Sur, Monterrey, NL 64849, Monterrey, Mexico

${ }^{\mathrm{c}}$ Department of Chemistry and Biochemistry, University of Toledo, Toledo, OH, 43606, USA

${ }^{\mathrm{d}}$ Department of Bioengineering, University of California San Diego, San Diego, CA, 92093-0412, USA.

e GlaxoSmithKline, Biopharmaceutical Analytical Sciences Department. King of Prussia, PA, 19406, USA.

Corresponding Author: *LJP and RFD are the corresponding authors and correspondence should be addressed at LJP1@unl.edu and delgadillo@itesm.mx, respectively. This work was carried out at Department of Chemistry, University of Nebraska-Lincoln, NE 68588-0304, USA.

Present Addresses: $\uparrow$ RFD is currently at Tecnologico de Monterrey, School of Engineering and Sciences, Av. Eugenio Garza Sada 2501 Sur, Monterrey, NL 64849, Monterrey, Mexico

Author Contributions: The manuscript was written through contributions of all authors. All authors have given approval to the final version of the manuscript. 
ABSTRACT: The high affinity $\left(\mathrm{K}_{\mathrm{D}} \sim 10^{-15} \mathrm{M}\right)$ of biotin to avidin and streptavidin is the essential component in a multitude of bioassays with many experiments using biotin modifications to invoke coupling. Equilibration times suggested for these assays assume that the association rate constant $\left(\mathrm{k}_{\mathrm{on}}\right)$ is approximately diffusion limited $\left(10^{9} \mathrm{M}^{-1} \mathrm{~s}^{-1}\right)$ but recent single molecule and surface binding studies indicate they are slower than expected $\left(10^{5}\right.$ to $\left.10^{7} \mathrm{M}^{-1} \mathrm{~s}^{-1}\right)$. In this study, we asked whether these reactions in solution are diffusion controlled, what reaction model and thermodynamic cycle described the complex formation, and the functional differences between avidin and streptavidin. We have studied the biotin association by two stopped-flow methodologies using labeled and unlabeled probes: I) fluorescent probes attached to biotin and biocytin; and II) unlabeled biotin and HABA, 2-(4'-hydroxyazobenzene)-benzoic acid. Native avidin and streptavidin are homotetrameric and the association data show no cooperativity between the binding sites. The $\mathrm{k}_{\mathrm{on}}$ values of streptavidin are faster than avidin but slower than expected for a diffusion limited reaction in both complexes. Moreover, the Arrhenius plots of the $\mathrm{k}_{\mathrm{on}}$ values revealed strong temperature dependence with large activation energies $(6-15 \mathrm{kcal} / \mathrm{mol})$ that do not correspond to a diffusion limited process $(3-4 \mathrm{kcal} / \mathrm{mol})$. The data suggest that the avidin binding sites are deeper and less accessible than those of streptavidin. Accordingly, we propose a simple reaction model with a single transition state for non-immobilized reactants whose forward thermodynamic parameters complete the thermodynamic cycle in agreement with previously reported studies. Our new understanding and description of the kinetics, thermodynamics and spectroscopic parameters for these complexes will help to improve purification efficiencies, molecule detection, and drug screening assays or find new applications. 


\section{INTRODUCTION.}

The extremely high affinity of biotin $\left(\mathrm{B}_{7}\right.$, vitamin $\left.\mathrm{H}\right)$ for avidin (AV) and streptavidin (SAV) is widely exploited in biotechnology and biochemistry in a vast array of applications. ${ }^{1,2}$ It has been used in molecular biology as markers to identify functional moieties in proteins, receptors ${ }^{3}$ and the development of bioprocessing affinity chromatography columns for the recovery of highly valued biomolecules. ${ }^{4}$ More recently, advances in the characterization of these complexes have allowed the development of highly specific immunoassays, biosensors, and "omic" tools for disease

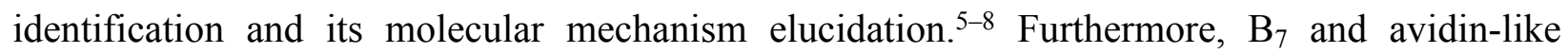
interactions can be exploited for imaging purposes in the development of assays in vivo and realtime visualization of intracellular or other type of biological processes ${ }^{9,10}$ and nanoscale drug delivery systems of small molecules, proteins, vaccines, monoclonal antibodies, and nucleic acids. ${ }^{11} \mathrm{SAV}$ and $\mathrm{B}_{7}$ are used in a Fluorescence Resonance Energy Transfer (FRET) ${ }^{12}$ systems for drug High Throughput Screening (HTS) applications, commercially know as Homogeneous TimeResolved Fluorescence (HTRF). ${ }^{13-15}$ Furthermore, it has been suggested that these proteins function in nature as antimicrobial agents by depleting $\mathrm{B}_{7}$ or sequestering bacterial and viral DNA, ${ }^{16,17}$ and questions concerning their biological importance increase as new avidin-like proteins are discovered. For example, rhizavidin was discovered from proteobacterium Rhizobium etli, ${ }^{18,19}$ tamavidin from the basidiomycete fungus Pleurotus cornucopiae, ${ }^{20}$ xenavidin from the frog Xenopus tropicalis, ${ }^{21}$ bradavidin from Bradyrhizobium japonicum, ${ }^{22,23}$ and other AV related proteins have been isolated from chicken, Gallus gallus. ${ }^{24-28}$

The monomers of AV and SAV are eight stranded anti-parallel beta-barrels with several aromatic residues forming the biotin binding site at one end of the barrel. ${ }^{29}$ Two monomers lie parallel to each other forming a dimer with an extensive interface and two dimers associate forming 
the weaker interface of the homotetramer. The apo-tetramer has modest thermal stability and the protein becomes highly thermal stable with ligand bound. ${ }^{30}$ Intriguingly, the dimeric interface appears to be necessary for high affinity. Introducing two interface mutations, Trp110 to Lys to form dimers of high affinity plus Asn54 to Ala to form monomers, that remains monomeric with ligand bound, that have a significantly reduced affinity $\left(K_{D} \sim 10^{-7} M\right) .{ }^{31}$ The use of monomeric avidin in affinity chromatography allows for reversible binding.

As it can be inferred, new applications for $\mathrm{B}_{7}$ :avidin related complexes will surely continue to emerge as more derivatives are characterized. However, to obtain reliable and sensitive applications; a better understanding of the thermodynamics, fluorescence behavior of the attached probes, kinetic reaction mechanisms of association and dissociation of $\mathrm{B}_{7}$ and avidin-like systems are surely need, which can used to improve purification efficacies, detection, drug screening assays, and develop new nanotechnological applications. Therefore, we want to provide a more global description of the AV-B and SAV-B systems for bio- and nano-technological applications.

The association rate constant of $\mathrm{B}_{7}$ binding to $\mathrm{AV}\left(\mathrm{k}_{\mathrm{on}}\right)$ is assumed to be near diffusion limited since it was first measured by Green ${ }^{32}\left(7.0 \times 10^{7} \mathrm{M}^{-1} \mathrm{~s}^{-1}, \mathrm{pH} 5\right.$ and $\left.25^{\circ} \mathrm{C}\right)$ employing a quenching experiment that required the quantification, by chromatographic separation, of un-reacted ${ }^{14} \mathrm{C}$ biotin. Since then several widely varying $\mathrm{k}_{\mathrm{on}}$ values have been reported for both AV and SAV ranging from $1 \times 10^{5} \mathrm{M}^{-1} \mathrm{~s}^{-1}$ to $2 \times 10^{8} \mathrm{M}^{-1} \mathrm{~s}^{-1} 20,33-36$ with error ranges below $10 \%$.

Despite this information, the kinetic and thermodynamic parameters of the $\mathrm{B}_{7}$ association to these AV and SAV proteins have not been studied in systematic detail. Consequently, for this study, we asked whether the association rate constants $\left(k_{\text {on }}\right)$ for $\mathrm{B}_{7}$ binding to $A V$ and $S A V$ are actually diffusion controlled, what are the association model and thermodynamic cycle that describe the reaction process, and the functional differences between $A V$ and $S A V$. We analyzed 
the $\mathrm{k}_{\mathrm{on}}$ for $\mathrm{B}_{7}$ binding to $\mathrm{AV}$ and SAV by two stopped-flow (SF) methodologies employing fluorescent dye labeled- and unlabeled-B derivatives. In the first case, the association reactions were monitored with two sensing modalities: Fluorescence change, $F(t)$, and corrected fluorescence anisotropy, $\mathrm{rF}(\mathrm{t})$, under pseudo-first-order conditions as a function of temperature, concentration, and $\mathrm{pH}$ with the help of three dye-labeled $\mathrm{B}_{7}$ probes: 1) Biotin-4-fluorescein (BFl), 2) Oregon green 488 ® biocytin $(\mathrm{BcO})$, and 3) biotin-DNA $\mathrm{ds}^{*} \mathrm{Fl}-3$ ' (Figure 1). The functional cofactor form of $\mathrm{B}_{7}$ is biocytin $(\mathrm{Bc})$ which is formed through an amide linkage between the $\varepsilon$ amine of lysine and carboxyl group of biotin. Modified $\mathrm{BcO}$ contains a significantly longer linker with respect to $\mathrm{BFl}$ which allows analysis of a potential steric effect in the association process, as has been reported elsewhere. ${ }^{37}$

We also studied the effect of AV glycosylation by removing, enzymatically, the carbohydrate motif to compare the respective association rates with those of the untreated AV, SAV and analogous probes in other studies. ${ }^{20,33-36}$ We show that the binding polynomial distribution $(Z)$ of the dye-labeled $\mathrm{B}_{7}$ complexes to track bound tetrameric species that appeared after SF mixing at pseudo first order conditions corresponding to high excess protein levels. We make a distinction of the AV and SAV complexes using a simple filling model $\mathrm{AB}_{\mathrm{n}}$ where $\mathrm{A}$ is either $\mathrm{AV}$ or $\mathrm{SAV}$, and " $\mathrm{n}$ " is the total available number of binding sites occupied by the dye-labeled $\mathrm{B}_{7}$ probes and not the Hill number associated with cooperative binding.

For the second methodology, using a relaxation kinetics approach, the association reactions of unlabeled $\mathrm{B}_{7}$ was monitored in SF instrumentation by tracking the absorbance changes of an AVHABA complex as $\mathrm{B}_{7}$ replaces bound HABA. ${ }^{38}$ The presence of ligand stabilizes the avidin tetramer. AV-HABA relaxation experiments were used to determine if stabilizing the tetramer affects the association rate constants and cooperativity. 
Global fitting of the kinetic traces and reported calorimetry values allowed us to test reaction models and discriminate the most probable reaction mechanism, as carried out by some of us in previous studies. ${ }^{39-42}$ Consequently, the respective activation energies calculated by Arrhenius plots of association rates allowed the acquisition of the forward thermodynamic parameters toward the transition state: enthalpy ( $\mathrm{E}_{\mathrm{a}}^{\text {forward }}$ or $\Delta \mathrm{H}^{\ddagger}$, forward $)$, entropy $\left(\Delta \mathrm{S}^{\ddagger}\right.$, forward $)$ and Gibbs energy $\left(\Delta \mathrm{G}^{\ddagger}\right.$, forward) of AV and SAV activated complexes. The forward thermodynamic data is in excellent agreement with the backwards thermodynamic values calculated with the dissociation rate constants $\left(\mathrm{k}_{\mathrm{off}}\right)$ reported by N. M. Green in his seminal work. ${ }^{32}$ Additionally, we explain the nature of the second dissociation phase first observed and correctly neglected by Green as a bimolecular "displacement" rate constant ( $k_{\text {displacement }}^{\text {off }}$, in addition to the detection of the documented unimolecular "replacement" rate constant $\left(k_{\text {replacement }}^{\text {off }}\right)^{26,32}$ which is used to establish the wellknown dissociation constant, $\mathrm{K}_{\mathrm{D}}$, as the most stable complex in nature.

Furthermore, we studied the changes in fluorescence lifetime $(\tau)$, quantum yield $(Q Y)$, dynamic quantum yield $(\Phi)$, dye emitting fraction (1-S) and steady state anisotropy $\left(\mathrm{r}_{\mathrm{ss}}\right)$ of the fluorescent probes before and after complex formation. These spectroscopic properties give indications of the chemical environment surrounding the $\mathrm{B}_{7}$ binding pocket in $\mathrm{AV}$ and $\mathrm{SAV}$ and have important relevance in fluorescence assay detection limits as the signal to noise ratio can be improved by careful choosing linker length and fluorescent probe. 


\section{EXPERIMENTAL PROCEDURES.}

2.1.1. Materials and solution conditions: Oregon green ${ }^{\circledR} 488$ Biocytin (lot 40300A, Figure 1) was from Invitrogen (Eugene, OR). Avidin (CAS 1405-69-2, lot 608540) was purchased from Calbiochem (La Jolla, CA). HABA or 2-(4'-hydroxyazobenzene)-benzoic acid (CAS 163482-8, lot 52F-0073), streptavidin (CAS 9013-20-1), endoglycosidase H (CAS 37278-88-9) and dbiotin (CAS 58-85-5, lot 13F-3199) were all purchased from Sigma Aldrich (St. Louis, MO). Biotin-4-fluorescein (lot 31005, Figure 1) was purchased from Biotium, Inc. (Hayward, Ca). The 3' end labeled fluorescein top strand with a modified biotinylated d-thymine at position 6 in the following sequence: 5'-GGGAA(biotin-dT)AACTTGGC*Fl-3' (Figure 1) and the respective complement (5'-GCCAAGTTATTCCC-3') were made by Tri-Link Biotechnologies, Inc. (San Diego, CA), and were both HPLC and PAGE purified. The sequences retain the G/C (base pairs) ends and fluorescein identical to those characterized extensively in our previous studies. $39,41,43$ The biotinylated 14 mer duplex (biotin-DNA ${ }_{\mathrm{ds}} * \mathrm{Fl}$ ) was formed with 5-10X excess complement and incubated for at least $20 \mathrm{~min}$.

2.1.2. The protein and active site concentrations of $A V$ and $S A V$ were determined with the HABA colorimetric assay of Green ${ }^{37}$ for which absorbance measurements, with total protein at $280 \mathrm{~nm}(1.54=1 \mathrm{mg} / \mathrm{ml})$ and HABA at $500 \mathrm{~nm}(35.5 \mathrm{mM \varepsilon}$ bound, $0.48 \mathrm{mM \varepsilon}$ unbound $)$ were made with a Cary 300 Bio UV-Vis spectrophotometer (Varian Inc., Palo Alto, CA). The occupancy of the dye-labeled probes on the AV and SAV tetramer ("p") was obtained with the expansion version of the normalized partition function, $Z=(p+q+x)^{4}$. In considering the totality of binding sites in the AV and SAV tetramer, let "p" denote the fraction of total sites occupied by $\mathrm{B}_{7}$ ligands (or HABA), "q" the fraction that are unoccupied and are available for binding, and " $\mathrm{x}$ " the fraction that are unavailable. The normalized partition function that describes the mole fractions of the 
various possible AV and SAV tetrameric species is given by $Z=(p+q+x)^{4}$; where " $x$ ", from the HABA assay for AV, was found to be 0.185 (or 18.5\%), and $q=1-p-x$. Knowing the total concentration of binding sites from UV protein absorbance and Green's methodology, ${ }^{37}$ and determining " $\mathrm{x}$ ", gives one the maximum value of " $p$ " that will be reached in reacting tetramers with a $\mathrm{B}_{7}$ analog. Expansion of $\mathrm{Z}$ gives the mole fractions of the various species in solution, and in decreasing order in terms of probe occupancy, are: $p^{4}+4 p^{3} q+4 p^{3} x+6 p^{2} q^{2}+6 p^{2} x^{2}+12 p^{2} q x+$ $4 p q^{3}+4 p x^{3}+12 p q^{2} x+12 p q x^{2}+q^{4}+x^{4}+4 q^{3} x+4 q x^{3}+6 q^{2} x^{2}$ which totals 1 . This development assumes completely random occupancy of probe and inactive sites characterized by " $\mathrm{x}$ ". The species containing one bound probe have " $p$ " raised to the first power; those with two bound probes have " $p$ " raised to the second power, and so on.

All of the following protein concentrations are presented on a binding site basis: The HABA association reactions for $\mathrm{AV}$ were measured at $23 \pm 0.1{ }^{\circ} \mathrm{C}$ with a concentration of $87 \mu \mathrm{M}$ HABA and $7.7 \mu \mathrm{M} A V$. The AV-HABA relaxation reactions were conducted with a preformed AVHABA complex made up of $200 \mu \mathrm{M}$ HABA and $10 \mu \mathrm{M} \mathrm{AV}$, flowed against varying amounts of biotin from $100 \mu \mathrm{M}$ up to $4000 \mu \mathrm{M}$ for a $[\mathrm{HABA}] /[\mathrm{B}]$ ratio that ranged from 0.05 to 2 .

2.1.3. The association stopped-flow reactions were carried out in a buffered solution of $10 \mathrm{mM}$ Tris- $\mathrm{HCl}, 100 \mathrm{mM} \mathrm{KCl}, 2.5 \mathrm{mM} \mathrm{MgCl}_{2}$ and $1 \mathrm{mM} \mathrm{CaCl}_{2}$ at $\mathrm{pH} 8$ and only $\mathrm{AV}-\mathrm{BcO}$ reactions included $\mathrm{pH} 9$ and 10 . The concentrations, after mixing, were of $20 \mathrm{nM}$ of dye-labeled biotin probe and $260 \mathrm{nM}, 520 \mathrm{nM}$ or $1040 \mathrm{nM}$ of AV; and for SAV of $200 \mathrm{nM}, 300 \mathrm{nM}, 400 \mathrm{nM}$ or $800 \mathrm{nM}$ at temperatures of $10,15,20$ and $25^{\circ} \mathrm{C}$. The deglycosylation of AV (for comparative association reactions) was carried out with endoglycosidase $\mathrm{H}^{44}$ with the standard protocol provided, both with and without incubation of a denaturant solution (2\% SDS and 1M 2mercaptoethanol). 
2.1.4. The dissociation reactions of dye-labeled biotin complexes were carried out with $\mathrm{AB}_{1}$ and $\mathrm{AB}_{4}$ preformed complexes. The $\mathrm{AB}_{1}$ complexes were created with $800 \mathrm{nM} \mathrm{SAV}$ and 40 $\mathrm{nM}$ of $\mathrm{BcO}$ or $\mathrm{BF} 1(\sim 11 \%$ mole fraction $)$ and for the $\mathrm{AB}_{4}$ complexes with $40 \mathrm{nM}$ SAV and $40 \mathrm{nM}$ of $\mathrm{BcO}$ or $\mathrm{BFl}$. The $\mathrm{AB}_{1}$ complexes, at $20 \pm 0.1^{\circ} \mathrm{C}$, were challenged with several concentrations of unlabeled $\mathrm{B}_{7}$ of $1500 \mathrm{nM}, 1750 \mathrm{nM}, 2000 \mathrm{nM}$ and $2500 \mathrm{nM}$, of which $760 \mathrm{nM}$ filled the remaining binding sites not occupied with the fluorescent probe and at $27 \pm 0.1{ }^{\circ} \mathrm{C}$, the total challenging $\mathrm{B}_{7}$ concentrations were of $1300 \mathrm{nM}, 1500 \mathrm{nM}, 1750 \mathrm{nM}, 2000 \mathrm{nM}$ and $3000 \mathrm{nM}$. The $\mathrm{AB}_{4}$ complexes, at $20 \pm 0.1^{\circ} \mathrm{C}$, were challenged with biotin concentrations of $400 \mathrm{nM}$ and 1600 nM.

2.1.5. The lifetimes $(\tau)$, steady state anisotropies $\left(r_{\underline{s}}\right)$, time-resolved anisotropies $\left(r_{t}\right)$ and quantum yields (QY) of the complexes (at $20 \pm 0.1^{\circ} \mathrm{C}$ and $\mathrm{pH} 8$ ) were collected with a dye-labeled $\mathrm{B}_{7}$ probe concentration of $20-40 \mathrm{nM}$ and $1040-2080 \mathrm{nM}$ of either protein (AV or SAV) to ensure that only one binding site in the tetramer was filled with a ligand $\left(\mathrm{AB}_{1}\right.$ filling model).

\subsection{Methodologies:}

2.2.1. Steady-state anisotropy $\left(r_{\underline{s}}\right)$ measurements were collected using the GiblinParkhurst modification of the Wampler-Desa method as described previously. ${ }^{45}$ The fluorescence signal was detected in a model A-1010 Alphascan fluorimeter (Photon Technologies, Inc., Birmingham, NJ) equipped with an R928 PMT (Hamamatsu, Bridgewater, NJ). The excitation was provided by an $\mathrm{Ar}^{+}$ion laser (Coherent Innova 70-4 Argon, Santa Clara, CA) at $488 \mathrm{~nm}$ and 5-10 $\mathrm{mW}$ of power incident on the sample. A photoelastic modulator (PEM-80; HINDS International, Inc., Portland, OR) was placed between the laser source and the sample compartment with a retardation level of $1.22 \pi$, and with the PEM stress axis orientated $45^{\circ}$ with respect to the E vector of the laser beam. Two signals were acquired with the PEM alternating between "on" and 
“off" positions for 10 seconds and the data fitted to a least squared straight line to minimize noise and at least six of these independent measurements were averaged to acquire the $\mathrm{r}_{\mathrm{ss}}$ values. The fluorimeter $\mathrm{G}$ factor was determined using a film polarizer and analyzer with an excitation at 488 nm provided by a xenon arc lamp (model A1010, Photon Technologies Inc, Princeton, NJ). The dissociation reactions of dye-labeled $\mathrm{B}_{7}$ and protein complexes were monitored by fluorescence changes and were also collected in the fluorimeter described above.

2.2.2. Fluorescence lifetimes $(\tau)$ and time-dependent anisotropy decays $\left(r_{t}\right)$ were collected in a FluoTime100 fluorescence spectrometer (PicoQuant, GmbH, Berlin, Germany) with the excitation light source provided by a picosecond pulsed diode laser (PicoQuant, GmbH, Berlin, Germany) at $470 \mathrm{~nm}$ and $20 \mathrm{MHz}$. The emission was collected at $520 \mathrm{~nm}$ through a non-fluorescing $520 \mathrm{~nm}$ interference filter (Oriel Corp., Stratford, CT) followed by a liquid filter of $1 \mathrm{~cm}$ path length containing $24 \mathrm{mM}$ acetate buffered dichromate at $\mathrm{pH} 4$, placed between the sample and detector to eliminate traces of excitation light. ${ }^{39}$ The fluorescence decays were fit by a nonlinear leastsquares minimization based on the Marquardt algorithm embedded in the Fluofit software (PicoQuant GmbH). Twenty-eight decays were collected per sample; they were grouped in four sets, each set consisted of seven sample decays and one Instrument Response Function, IRF, for deconvolution proposes. The sets were globally fitted to mono- or bi-exponential decay models that were discriminated using the statistical parameter $\chi^{2}$. The $r_{t}$ data was acquired with the fluorimeter described above equipped with a polarizer and an analyzer to acquire the parallel VV(t) and perpendicular $\mathrm{VH}(\mathrm{t})$ decays. The PicoQuant $\mathrm{G}$ factor was calculated according to: $\mathrm{G}=\int H V(t) d t / \int H H(t) d t$, where $H V(t)$ and $H H(t)$ were the decays collected with the emission polarizer selecting vertical and horizontal E-vector passing orientations, respectively; and the excitation polarizer set for horizontally polarized excitation. 
2.2.3. Quantum yields $(Q Y)$ were obtained by using a reference fluorophore of known quantum yield and were calculated according to Parker and Rees, ${ }^{46,47}$ where the reference dye was fluorescein in $0.1 \mathrm{~N}$ sodium hydroxide solution. ${ }^{38}$ The emission fluorescence scans were collected from $480 \mathrm{~nm}$ to $700 \mathrm{~nm}$ with the excitation light set at $460 \mathrm{~nm}$ provided by the xenon arc lamp described above. These measurements were made on the $\mathrm{AB}_{1}$ complexes at high protein concentration.

2.2.4. The intrinsic lifetime $\left(\tau^{\circ}\right)$, dynamic quantum yield $(\Phi)$ and the fraction of nonstatically quenched molecules $(1-S)$ calculations have been described elsewhere ${ }^{43}$ and were acquired for the $\mathrm{AB}_{1}$ complexes. The HABA association reaction for $\mathrm{AV}$ was carried out under pseudo-first order conditions on a micro absorbance SF instrument ${ }^{48}$ equipped with a xenon arc lamp (described above) and a monochromator (model 82-410, Jarrel-Ash, Waltham, Mass.) set at $500 \mathrm{~nm}$.

2.2.5. The relaxation kinetics of unlabeled biotin reacting with the AV-HABA complexes were prepared at concentrations in which HABA occupies all sites (AV-HABA $)$. Biotin replaces HABA relative to the $k_{\text {off }}$ of the dye as shown for the first step (Eqn. 1) and then repeated for all sites. Having greater affinity, $\mathrm{B}_{7}$ occupies all sites at the end of the reaction and the measured $k_{\text {on }}$ is related to the affinities of the ligand bound (R-state) protein.

$$
A V-H A B A_{4}+B \underset{k^{\widehat{A V}-H_{1} A B A 3}}{\stackrel{k^{A V-H A B A 4}}{\longrightarrow}} A V-H A B A_{3}^{-1}+H A B A+B \stackrel{k_{o n}^{B}}{\rightarrow}\left(B-A V-H A B A_{3}\right)+H A B A \quad \text { Eqn. } 1
$$

The reaction is monitored by the HABA absorbance changes at $500 \mathrm{~nm}$ as it is replaced by unlabeled $\mathrm{B}_{7}$; yielding the relaxation constant of the reaction (R, Eqn. 2) which contains information of the biotin association rate constant of the R-state open binding site, $k^{A V-H A B A 3}$ to form a full saturated complex $\left(\mathrm{AV}-\mathrm{HABA}_{4}\right)$ and the dissociation rate of that full complex, 
$k^{A V-{ }_{-1}^{H A B A 4}}$, to yield a complex with three HABA molecules (AV-HABA 3 ). In subsequent steps, biotin replaces $\mathrm{HABA}$ as the ligand but the release of HABA creating an unoccupied site remains the same treating the reaction on a per monomer basis. The experiment was designed to acquire the pseudo first order association rate constant of $\mathrm{B}_{7}$ binding $\left(k_{o n}^{B}\right)$ to the R-state binding site in a complex occupied by HABA molecules $\left(\mathrm{AV}-\mathrm{HABA}{ }_{4}\right)$.

$$
R=\frac{k^{A V-{ }_{-1} A B A 4} \cdot k_{o n}^{B} \cdot[B]}{[H A B A] \cdot k^{A V-H_{1} A B A 3}+k_{o n}^{B} \cdot[B]}
$$

The reciprocal of the relaxation constant $(1 / \mathrm{R})$ is plotted vs. the $[\mathrm{HABA}] /[\mathrm{B}]$ concentration ratio (Eqn. 3) allowing to calculate: $k^{A V-{ }_{-1}^{H A B A 4}}$ and $k^{A V-H_{1}^{H A B A 3}}$ by solving for the intercept (

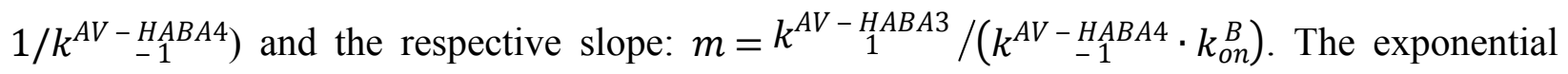
decays were analyzed by the method of Foss. ${ }^{49}$ There was no departure from simple first order decay in the relaxation, justifying the use of the following simple model and equations.

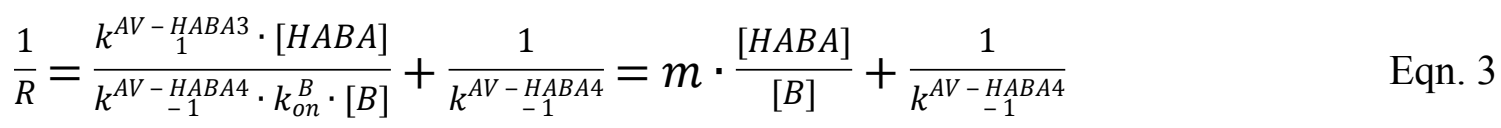

2.2.6. The association reactions of dye-labeled biotin and $A V$ (or $S A V$ ) were collected with a SF instrument, described previously. ${ }^{50,51}$ The fluorescence signal was collected through a $520 \mathrm{~nm}$ interference filter (Oriel Corp., Stratford, CT) with a detector time constant and SF dead time of $1 \mu \mathrm{s}$ and $1 \mathrm{~ms}$, respectively. The excitation light was provided by the Coherent $\mathrm{Ar}^{+}$ion laser (described above) at $488 \mathrm{~nm}$ with $15-10 \mathrm{~mW}$ of incident power on the reaction cuvette. The laser source was followed by the photo-elastic modulator described above with the axis oriented $45^{\circ}$ with respect to the electric vector of the incident light and with the half-wave modulation (50 $\mathrm{kHz}$ ) set for $488 \mathrm{~nm}$ excitation. The demodulation circuitry following the photomultiplier provided a $\mathrm{DC}(\mathrm{t})$ and a rectified $\mathrm{AC}(\mathrm{t})$ which were converted to digital data by a high-speed digitizer (PCI- 
5122) from National Instruments (Austin, TX) with 14-bit resolution and $100 \mathrm{MHz}$ bandwidth, through channels 0 and 1 . The data acquisition was controlled by LabVIEW ${ }^{\mathrm{TM}}(\mathrm{Vr} 8)$ software at a collection rate of 6120 data points/second and stored in spreadsheets. The AC(t) and DC(t) data were baseline corrected before obtaining the signal ratio (Eqn. 4) as a function of time $\left(\rho_{t}\right)$.

$\rho(t)=\frac{A C(t)}{D C(t)}=\frac{1.5 \cdot r(t) \cdot A_{\text {Gain }}}{1-0.47818 \cdot r(t) \cdot(1+2.3806 \cdot H)}$

The constant $A_{\text {Gain }}$ is the instrumental amplitude gain and was evaluated by solving $\rho(t)$ using the known steady state anisotropy $\left(\mathrm{r}_{\mathrm{ss}}\right)$ of the complexes which is equivalent to the $\mathrm{r}(\mathrm{t})$ at $\mathrm{t}=\infty$; and $\mathrm{H}$, obtained from the equivalent grating factor $(\mathrm{G})$ for the filters and photo multiplied tubes in the SF. For the probes used in here $\mathrm{G}$ was 0.82 and $\mathrm{H}=(1-\mathrm{G}) /(1+\mathrm{G})=0.099$. Knowing $\mathrm{A}_{\text {gain }}$ and $\mathrm{H}$, the $\mathrm{AC}(\mathrm{t})$ and $\mathrm{DC}(\mathrm{t})$ signals can be solved for $r(t)$ and $F(t)$ (Eqn. 4 and 5) and the normalized fluorescence, $\bar{F}(t)$, and corrected fluorescence anisotropy, $\overline{r F}(t),{ }^{52}$ were obtained when $\bar{F}(0)$ and $\overline{r F}(0)$ were scaled to 1 at $\mathrm{t}=0$.

$F(t)=\frac{D C(t)}{1-0.47818 \cdot r(t) \cdot(1+2.3806 \cdot H)}$

Eqn. 5

The $\bar{F}(t)$ (Eqn. 6) is equivalent to $\left(\mathrm{I}_{\mid}\right)+2\left(\mathrm{I}_{\perp}\right)$ and proportional to quantum yield $\left(\mathrm{QY}_{\mathrm{i}}\right)$, molar absorptivity $\left(\varepsilon_{\mathrm{i}}\right)$ and to the formation or disappearance of the emitting species $\mathrm{X}_{\mathrm{i}}(\mathrm{t})$; and $\overline{r F}(t)$ including the steady state anisotropies $\left(\mathrm{r}_{\mathrm{ss}}\right)$ of each fluorescent species (Eqn. 7). ${ }^{52}$

$\bar{F}(t)=\sum \varepsilon_{i} \cdot Q Y_{i} \cdot X_{i}(t) / \sum \varepsilon_{i} \cdot Q Y_{i} \cdot X_{i}(0)=F(t) / F(0) \quad$ Eqn. 6

$\overline{r F}(t)=\sum \varepsilon_{i} \cdot r_{i, s s} \cdot Q Y_{i} \cdot X(t)_{i}=r F(t) / r F(0)$

2.2.7. The biotin association reaction model for $A V$ and $S A V$ was discriminated by the squared residuals of the observed and calculated association traces of both fluorescence and 
anisotropy fluorescence signals, $\bar{F}(t)$ and $\overline{r F}(t)$, respectively. For the labeled biotin probes: BFl and $\mathrm{BcO}$ probes, the association reactions were very well described by the simplest possible model (Eqn. 8) with single association rate constants $\left(\mathrm{k}_{\mathrm{on}}\right)$.

$A V($ or $S A V)+$ Dye-labeled Biotin $\stackrel{k_{o n}}{\rightarrow}$ Complex

Eqn. 8

In the case of the biotin-DNA ${ }_{\mathrm{ds}} * \mathrm{Fl}$, the association reaction model was complemented by second $\mathrm{k}_{\mathrm{on}}$ which resulted in a system of two parallel reactions (Eqn. 9). In both cases, the backward reaction is not significant during the 5-8 sec required for the biotin association binding. $A V($ or $S A V)+\left(\text { Biotin-DNA } A_{d s}^{*} F l\right)_{1} \stackrel{k_{o n 1}}{\longrightarrow}$

$A V($ or $S A V)+\left(\text { Biotin-DNA } A_{d s}^{*} F l\right)_{2} \stackrel{k_{\text {on } 2}}{\longrightarrow}$ Complex

2.2.8. The dissociation reactions of the complexes were followed by fluorescence changes, $\overline{\mathrm{F}}(\mathrm{t})$, in the fluorimeter and laser setup described above and tuned to $488 \mathrm{~nm}$ under discontinuous excitation to prevent photobleaching distortion. The signal was best fitted to the following dissociation model (Eqn. 10), in which the dye labeled complex dissociates into the labeled $\mathrm{B}_{7}$ probe $(\mathrm{BFl}$ or $\mathrm{BcO})$ and the respective protein ( $\mathrm{AV}$ or $\mathrm{SAV}$ ).

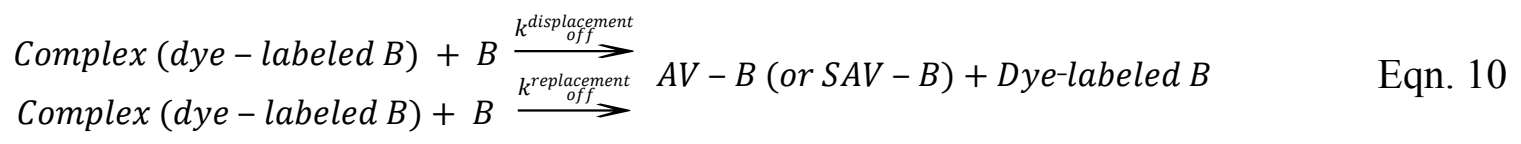

2.2.9. Time-resolved anisotropy $\left(\bar{r}_{t}\right)$ was calculated according to Eqn. 11 where the preexponential " $f$ " corresponds to the slow phase that derives from the lifetime of the global motion $\left(\tau_{\mathrm{G}}\right)^{53}$ which was fitted within a range of expected correlation time for the complex size; ${ }^{54}$ consequently, facilitating resolution of the fast correlation lifetime $\left(\tau_{\mathrm{p}}\right)$ and the corresponding preexponential $(1-f)$.

$\bar{r}(t)=(1-f) \cdot \exp \left(-\frac{t}{\tau_{p}}\right)+f \cdot \exp \left(-\frac{t}{\tau_{G}}\right)$ Eqn. 11 
The $f$ parameter was constrained to the observed $\mathrm{r}_{\text {ss }}$ (Eqn. 12) where $\hat{F}(t)$ (Eqn. 13) is normalized $\left(\alpha_{1}+\alpha_{2}=1\right)$ and derived from the observed fluorescence decays of the complex. ${ }^{55}$

$r_{s S}=0.4 \int \bar{r}(t) \cdot \hat{F}(t) d t$

Where

$\hat{F}(t)=\frac{\alpha_{1} \exp \left(-\frac{t}{\tau_{1}}\right)+\alpha_{2} \exp \left(-\frac{t}{\tau_{2}}\right)}{\alpha_{1} \tau_{1}+\alpha_{2} \tau_{2}}$ Eqn. 13

In a simple model, the transition moment is assumed to wobble within a cone of semi-apical angle $\Omega,{ }^{56}$ where the cone axis is normal to the surface of a sphere that corresponds to the macromolecule. The angle $\Omega$ is calculated from Eqn. 14 .

$f=\left[\frac{1}{2} \cos \Omega \cdot(1+\cos \Omega)\right]^{2}$

Eqn. 14

\section{RESULTS AND DISCUSSION.}

3.1 Active avidin binding sites: Avidin and streptavidin are tetramers in solution. If the binding of ligand is positively cooperative, differences in $k_{\text {on }}$ for initial (T-state) and final (R-state) binding steps could be significant and therefore comparison of initial binding by unliganded avidin and final binding by liganded avidin is necessary. Measurement of the initial binding rate requires ligand free avidin but endogenous ligand could potentially interfere. In fact, AV preparations often present about $20 \%$ of the inactive sites for the binding of any $\mathrm{B}_{7}$ analogs, either because they contain endogenous $\mathrm{B}_{7},{ }^{37}$ or perhaps existence of damaged binding sites in some of them, e.g., tryptophan oxidation. ${ }^{57}$ To acquire accurate $\mathrm{k}_{\mathrm{on}}$ values, the actual available binding site concentration for each sample was measured by HABA colorimetric assays in relation with absorbance at $280 \mathrm{~nm}$. Accordingly, the percentage of available active sites of AV and SAV were $81.5 \pm 0.5 \%$ and $94.0 \pm 1.0 \%$ with respect to total protein, respectively, which were in excellent agreement with the $82 \%$ and $95 \%$ reported by the commercial source (Sigma Aldrich and 
CalBiochem). The SF apparatus provided rapid thorough mixing of the probes with AV and SAV allowing measurement of the full reaction. The issue of rapid mixing vs. more conventional titrations was treated previously. ${ }^{48}$ In the SF association measurements, the dye-labeled $\mathrm{B}_{7}$ probes were sub-stoichiometric to determine the initial (T-state) binding rates (e.g. $20 \mathrm{nM}$ of $\mathrm{BFl}, \mathrm{BcO}$ and biotin-DNA ${ }_{\mathrm{ds}}{ }^{*} \mathrm{~F} 1$ vs. $260 \mathrm{nM}, 520 \mathrm{nM}$ and $1040 \mathrm{nM}$ in binding sites basis). Limiting the ligand also reduces several potential measurement artifacts including FRET self-transfer, and contact interference including probe fluorescence quenching by contact interactions ${ }^{58}$ in the $\mathrm{AB}_{2}, \mathrm{AB}_{3}$ or $\mathrm{AB}_{4}$ complexes; especially for the $\mathrm{BcO}$ which has a longer linker. ${ }^{59}$ Using the binding polynomial for the $20 \mathrm{nM}$ probe after mixing, and for the intermediate AV concentration, $638 \mathrm{nM}$ in total sites, $520 \mathrm{nM}$ in available sites, the mole fraction of species with a single bound probe is 0.114 , that with two bound is 0.0055 , with three bound is 0.00012 , so at most, only $4.6 \%$ of the molecules with bound AV contain two probes; for $1040 \mathrm{nM}$ available sites, the value drops to $2.3 \%$. With limited occupancy, the association reactions acquired the dye-labeled $\mathrm{B}_{7}$ probes reflect the binding to the first binding site (T-state) in the tetramer for the SF experiments. Unlabeled $\mathrm{B}_{7}$ relaxation kinetic experiment was designed to observe the binding at the final site (R-state), as discussed below.

\subsection{Association rate constants $\left(k_{\text {on }}\right)$ of biotin binding to apo-avidin:}

3.2.1. Dye-labeled biotin association rate constants by stopped-flow methodology. The fluorescence $\bar{F}(t)$ and corrected anisotropy association binding traces, $\overline{r F}(t)$, properly monitored the association reactions, as they yielded equivalent $\mathrm{k}_{\mathrm{on}}$ values (Table 1) and presented the best optimal fit residuals (Figure 2). In contrast to the anisotropy signal, $\bar{r}(t)$, that lagged behind $\bar{F}(t)$ and $\overline{r F}(t)$ owing to changes in the quantum yield (QY) of the involved fluorescence species. ${ }^{52}$ These three types of association binding traces were acquired with discontinuous excitation that circumvented photobleaching (Figure 3) allowing the detection of all non-photobleaching rate 
constants. Consequently, the $\mathrm{k}_{\mathrm{on}}$ values of AV showed linear concentration dependence (Figures 4) and strong temperature dependence when using the $\mathrm{BcO}$ (Figure 5) and BFl (Table 2) probes. Notably, a reduction in the $\mathrm{k}_{\text {on }}$ of $\sim 10 \%$ was observed with each $\mathrm{pH}$ unit increment (from 8 to 10) which may derive from titration of the hydrogen bonding of asparagine and tyrosine in the binding pocket. ${ }^{29}$

3.2.2. Unlabeled biotin association rate constants by relaxation kinetics methodology. The experiment consisted in challenging a pre-saturated AV-HABA complex with $\mathrm{B}_{7}$ (Figure 6) to measure the association rate of the final "relaxed" binding sites which yielded a $k_{\text {on }}^{B}$ of $5.3 \pm 0.9 \times$ $10^{6} \mathrm{M}^{-1} \mathrm{~s}^{-1}$ (at $\mathrm{pH} 8$ and $23{ }^{\circ} \mathrm{C}$ ) which slightly slower than the $7.8 \pm 0.4 \times 10^{6} \mathrm{M}^{-1} \mathrm{~s}^{-1}$ acquired with $\mathrm{BcO}$ (Arrhenius plot, $23^{\circ} \mathrm{C}$ and $\mathrm{pH}$ 8) indicating non-cooperativity (or slightly negative) for binding site association rates. The HABA dissociation rate constant of the AV-HABA 4 complex

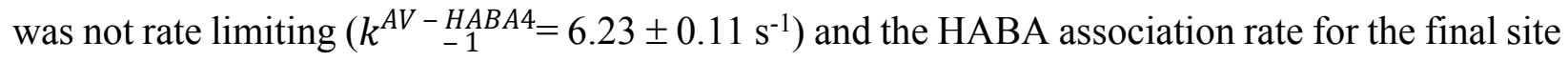
was $k_{1}^{A V-\underset{1}{H} A B A 3}=5.1 \pm 0.1 \times 10^{5} \mathrm{M}^{-1} \mathrm{~S}^{-1}$ which results in a AV-HABA equilibrium constant of $\mathrm{K}_{\mathrm{D}}$ $\mathrm{AV}-\mathrm{HABA}=12.2 \pm 0.3 \times 10^{-6} \mathrm{M}$ similar to that reported by Green ${ }^{57}$ at $\mathrm{pH} 8$ which support the quality of our relaxation kinetic experiment.

3.2.3 Non-cooperative biotin binding to avidin sites. The association reactions that used the fluorescent probes $\mathrm{BFl}$ and $\mathrm{BcO}$ monitored the $1^{\text {st }}$ available binding site, as they were carried out at pseudo first order, at very high protein concentration with low occupancy for $\mathrm{AB}_{1}$ filling model, as discussed above. In contrast, the relaxation kinetic methodology scrutinized the unlabeled $\mathrm{B}_{7}$ binding to the unoccupied site while the 3 remaining sites were filled with HABA, this process can be thought as the binding of $\mathrm{B}_{7}$ to the $4^{\text {th }}$ binding site. Therefore, the data obtained with dye-labeled $B_{7}$ probes and unlabeled $B_{7}$ should report the binding rates to the $1^{\text {st }}$ and $4^{\text {th }}$ sites. Since these two values only diverge by $32 \%$ we believe that there is not significant cooperativity 
nor an intrinsic difference in any of the AV sites. If a protein has two forms, high (R) and low (T) affinity, ${ }^{60}$ the HABA bound ligand will hold the AV protein in the R-state. In the relaxation experiments, all the bound $\mathrm{HABA}$ get replaced by dye-labeled $\mathrm{B}_{7}(\mathrm{BFl}$ or $\mathrm{BcO})$ but all the sites are R-state meaning that there is not switching from $\mathrm{T}$ to $\mathrm{R}$. This is the same as $\mathrm{HbO}_{2}$ flowed against $\mathrm{CO}$, where $\mathrm{O}_{2}$ gets replaced by $\mathrm{CO}$ but not biphasic because no T-state is present. ${ }^{60,61}$ As $\mathrm{B}_{7}$ binding to $\mathrm{AV}$ and $\mathrm{SAV}$ is non-cooperative, the HABA replacement is a pseudo first order measure of the $\mathrm{B}_{7}$ association rate and as should be the same or close to the association rate of the dye-labeled $\mathrm{B}_{7}$ flowed against empty AV or SAV, and our values differed only by $32 \%$ for these two approaches.

3.2.4 Comparisons with other AV-B kinetic studies were carried out at the possible closest condition; thus, at $25^{\circ} \mathrm{C}$ and $\mathrm{pH} 8$, the $\mathrm{BFl}$ and $\mathrm{BcO}$ association rate constants, $\mathrm{k}_{\mathrm{on}}$, were 3.8 and $7.4 \times$ slower than the $7 \times 10^{7} \mathrm{M}^{-1} \mathrm{~s}^{-1}$ reported by N. M. Green ${ }^{32}$ (at $25^{\circ} \mathrm{C}$ and $\mathrm{pH} 5$ ), respectively. However, a larger uncertainty is expected for the latter experiment because it was not carried out using rapid mixing techniques forcing the usage of very low $\left({ }^{14}\right.$ carbon) $\mathrm{B}_{7}$ concentrations (picomolar range) to stop the reaction timely and quantify the un-reacted probe. Consequently, Green's experiment was an extremely tedious task that was carried out, only once and at one temperature. On the other hand, a more recent association rate constant of $2.0 \pm 0.3 \times$ $10^{6} \mathrm{M}^{-1} \mathrm{~S}^{-1}$ was obtained in a Surface Plasmon Resonance study (SPR) ${ }^{20}$ at $20{ }^{\circ} \mathrm{C}$ and a pH 7.4 in HEPES buffer. This independent $\mathrm{k}_{\text {on }}$ value was $\sim 9$ and $\sim 5 \times$ slower than the ones acquired by us for $\mathrm{BFl}$ and $\mathrm{BcO}$, respectively. Nevertheless, it has been acknowledged previously that the SPR results are, controversially, too low to be accurate..$^{20,36}$ due to fixation to the chip of one of the reactants, generally AV or SAV. 


\subsubsection{Effect of $A V$ glycosylation on the biotin binding kinetics: AV has a glycan attached} to asparagine 17 at each tetrameric subunit which is composed of four or five mannoses and three N-acetylglucosamines. ${ }^{62}$ These sugar modifications are typically removed to improve crystallization but the glycan effect on the association binding rate of $\mathrm{B}_{7}$ was previously unknown. Interestingly, after enzymatic removal of the carbohydrates, the $\mathrm{k}_{\mathrm{on}}$ values of the de-glycosylated AV matched with those of natural glycosylated AV for the dye-labeled $B_{7}$ probes: e.g., $3.7 \pm 0.3$ $\times 10^{-6} \mathrm{M}^{-1} \mathrm{~s}^{-1}$ vs. $3.9 \pm 0.3 \times 10^{-6} \mathrm{M}^{-1} \mathrm{~s}^{-1}$ of $\mathrm{BcO}$ binding to de-glycosylated $\mathrm{AV}$ and untreated $\mathrm{AV}$ at $15{ }^{\circ} \mathrm{C}$, respectively. A previous study already suggested that the sugar chain is not required for $\mathrm{B}_{7}$ binding ${ }^{62}$ and now we confirm that $\mathrm{AV}$ glycosylation has no influence on the rate constants.

\subsection{Association reaction of unlabeled and dye-labeled biotin binding to streptavidin:}

\subsubsection{Dye-labeled biotin association reactions to SAV presented temperature (Figure 4C}

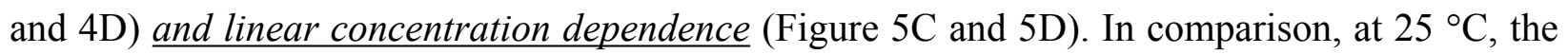
$\mathrm{k}_{\mathrm{on}}$ values of SAV were $4 \mathrm{X}$ and $3.2 \mathrm{X}$ faster than those observed for $\mathrm{B}_{7}$ binding to $\mathrm{AV}$ when reacting with $\mathrm{BFl}$ and $\mathrm{BcO}$, respectively. However, the temperature dependence was weaker than that observe for AV which indicated a profound difference in the binding site properties of these two proteins. Thus, SAV should be a more robust system for purification applications as variations on the temperature incubation protocols has less negative significant effects in the yield.

\subsubsection{Comparisons with other SAV-B association kinetic studies: An independent SF}

study tracked the binding of unlabeled $\mathrm{B}_{7}$ by fluorescence quenching of the tryptophan (Trp) of SAV, yielding a $\mathrm{k}_{\text {on }}$ of $7.5 \pm 0.6 \times 10^{7} \mathrm{M}^{-1} \mathrm{~s}^{-1}$ (at $25^{\circ} \mathrm{C}$ and $\left.\mathrm{pH} 7\right)^{36}$ which was in excellent agreement with $7.5 \pm 0.2 \times 10^{7} \mathrm{M}^{-1} \mathrm{~s}^{-1}$ for the $\mathrm{BFl}$ probe (at $25^{\circ} \mathrm{C}$ and $\mathrm{pH} 8$ ). This finding strongly indicates that the attached dyes are innocuous and dependably monitor the $\mathrm{B}_{7}$ binding to SAV and presumably to AV. In addition, the absence of any detectable intermediate in the association 
reaction in both cases is remarkable, since we monitored the initial binding of $\mathrm{B}_{7}$ and $\mathrm{SAV}$ using the fluorescence change and fluorescence anisotropy signals, and the independent tryptophanquenching study the final docking of $\mathrm{B}_{7}$ near the Trp. Conversely, there is another independent Surface Plasma Resonance (SPR) study of immobilized $\mathrm{B}_{7}$ binding to SAV that yielded a slower $\mathrm{k}_{\text {on }}$ of $5.13 \times 10^{6} \mathrm{M}^{-1} \mathrm{~s}^{-1}$ at $4{ }^{\circ} \mathrm{C},{ }^{63}$ which was $\sim 5 \mathrm{X}$ slower than our $2.6 \times 10^{7} \mathrm{M}^{-1} \mathrm{~s}^{-1}$ at $4{ }^{\circ} \mathrm{C}$, calculated by an Arrhenius plot (ln $k_{\text {on }}$ vs $1 / \mathrm{T}$ ) of the BFl data. Similarly to AV, we believe that SPR methodology for the $\mathrm{B}_{7}$ and $\mathrm{AV}$-like protein kinetics ${ }^{20,36}$ are modified by the immobilization of one reactant, either $\mathrm{B}_{7}$ or protein, to the chip.

\subsection{Biotinylated-duplex association reaction to $A V$ and $S A V$ :}

\subsubsection{The association rate constants of biotin attached to our biotin-14mer ${ }_{d s}{ }^{*} F l$. In case}

of biotinylated 14mer duplex showed a biphasic behavior with two temperature and concentration dependent rate constants (Table 2, Figure 7) when reacting with both AV and SAV. The biphasic association rate constants, $\mathrm{k}_{\mathrm{on} 1}$ and $\mathrm{k}_{\mathrm{on} 2}$, summed to approximately $70 \%$ of the total reaction amplitude. The remaining $\sim 30 \%$ was assigned to a third rate constant $\left(0.02 \pm 0.01 \mathrm{~s}^{-1}\right)$ that presented neither temperature nor concentration dependence; therefore, it has been assigned to the readjustments of the $\mathrm{Fl}$ dye after being displaced by both proteins. The $\mathrm{k}_{\mathrm{on} 1}$ and $\mathrm{k}_{\mathrm{on} 2}$ association rate constants of SAV were $3.4 \mathrm{X}$ and $1.8 \mathrm{X}$ faster than the corresponding rate constants of $\mathrm{AV}$ (Figure 8) as observed with the $\mathrm{BFl}$ and $\mathrm{BcO}$ probes, confirming the differences in the $\mathrm{AV}$ and SAV binding pockets.

\subsubsection{Comparisons with other biotinylated DNA kinetic studies. An independent FRET}

study monitored the reaction of $\mathrm{B}_{7}$ attached to the $5^{\prime}$ end of a 46 nucleotide duplex DNA binding to $\mathrm{SAV} .{ }^{35}$ The reaction also showed two rate constants at $\mathrm{pH} 8$, but at unspecified temperature, pre-exponentials and errors. To make a comparison, we have chosen SAV data at $20^{\circ} \mathrm{C}$ whose 
association rate constant, $\mathrm{k}_{\mathrm{on} 1}$, of $4.59 \pm 0.8 \times 10^{7} \mathrm{M}^{-1} \mathrm{~s}^{-1}$ was in excellent agreement with the 4.5 $\times 10^{7} \mathrm{M}^{-1} \mathrm{~s}^{-1}$ reported by the mentioned study. In the case of our $\mathrm{k}_{\mathrm{on} 2}$ of $2.33 \pm 0.1 \times 10^{6} \mathrm{M}^{-1} \mathrm{~s}^{-1}$, it was in good agreement with the second rate of $3.0 \times 10^{6} \mathrm{M}^{-1} \mathrm{~s}^{-1}$ of that independent study. The agreement in the data validates our findings which imply that $\mathrm{B}_{7}$ attached internally to DNA (or at the 5 , end) will have two rate constants, one enhanced and other diminished probably due to unfavorable orientation according to the reaction models discussed below.

3.5 Significance of the association rate constants: The $\mathrm{B}_{7}$ binding to AV and SAV (at $25^{\circ} \mathrm{C}$ ) were, respectively, between 54-714X and 13-400X slower than $10^{9} \mathrm{M}^{-1} \mathrm{~s}^{-1}$ as expected for a diffusion limited process. ${ }^{64}$ On the other hand, the $\mathrm{k}_{\text {on }}$ values of SAV were 3-4X faster than AV's despite the similarity of the AV and SAV binding sites in the crystal structures (Figure 8). Our deglycosylation experiments indicate that the disparity in the $\mathrm{k}_{\mathrm{on}}$ values between both SAV and AV proteins cannot be explained by the presence or absence of the carbohydrate motif on the AV but for true collective interactions of the aminoacids in the binding pocket and the biotin ring.

3.6 Biotin vs. Biocytin: In our study, the association rates were acquired with $\mathrm{B}_{7}$ and $\mathrm{Bc}$ probes, $\mathrm{BFl}$ and $\mathrm{BcO}$; respectively, in which Biocytin present a longer carbon linker; however, the values only differed by 2 -fold (Table 1 ), from $10^{\circ} \mathrm{C}$ to $25^{\circ} \mathrm{C}$, when reacting with AV. It is important to clarify that the association rates were not enhanced by the electrostatic attraction of the negative charged probes $(\mathrm{BFl}$ and $\mathrm{BcO})$ and the positive $\mathrm{AV} ;{ }^{29}$ since, the association rates of those two probes binding to neutral SAV differed also by $\sim 2$ fold as observed for AV. The dissociation constant, $\mathrm{K}_{\mathrm{D}}$, of $\mathrm{AV}-\mathrm{B}$ and $\mathrm{AV}-\mathrm{Bc}$ were reported to be $10^{-13}$ and $10^{-15} \mathrm{M}$, respectively, differing by 100 -fold. ${ }^{37}$ Consequently, this 100 -fold difference, if accurate, must be caused by a difference of 50 -fold in the $\mathrm{k}_{\mathrm{off}}$, dissociation rate constants which is discussed below. 
3.7 Dissociation kinetics. The dissociation reactions of the AV-B and SAV-B complexes had been described as passive unimolecular "replacements" ( $k_{\text {replacement }}^{\text {off }}$ ) with units of reciprocal seconds $\left(\mathrm{s}^{-1}\right)$ and values of $9 \times 10^{-8} \mathrm{~s}^{-1} 32$ and $2.4 \times 10^{-6} \mathrm{~s}^{-1},{ }^{65}$ respectively. However, we have also

observed a bimolecular "displacement" off-rate constants $\left(k_{\text {displacement }}^{\text {off }}\right)$ with $\mathrm{M}^{-1} \mathrm{~s}^{-1}$ units for the SAV-BcO complexes $\left(\mathrm{AB}_{1}\right.$ and $\left.\mathrm{AB}_{4}\right)$ that were strongly dependent of $\mathrm{B}_{7}$ concentration (Figure 9A) and temperature (Figure $9 \mathrm{~B}$ ). These reactions had $\sim 79 \%$ of the total release amplitude, in contrast to the $5 \%$ when $\mathrm{BFl}$ was used (Figure 9C); therefore, the longer "tail" of the $\mathrm{BcO}$ facilitated the displacement, a feature that can be exploited to increase purification yields. Also, the process is protein dependent, as it was not observed for the AV complexes. Significantly, this new information can find important applications in affinity chromatography purification based on SAV and longer "tail" or tethers that will help to increase the release of the product and enhance efficiency.

\subsection{Biotin reaction models to $A V$ and $S A V$ :}

3.8.1 Reaction model of $B F l$ and $B c O$ binding to $A V$ and $S A V$. The $\mathrm{SF}$ traces of $\mathrm{B}_{7}$ binding to AV and SAV were best fitted by a simple association model, $\mathrm{A}+\mathrm{B} \rightleftharpoons \mathrm{C}$. A single rate constant, $\mathrm{k}_{\text {on }}$ (Eqn. 8), could be fit with no intermediates or evidence of cooperativity considering that the dissociation reaction was not significant for the first 5-8 sec after mixing. More elaborate mechanism have been reported ${ }^{66,67}$. For example, $A+B \rightleftharpoons C \rightleftharpoons D$ has been proposed for polystyrene SAV coated particles $(6.5 \mathrm{nM})$ reacting with a fluorescein labeled biotin probe $(1.75 \mathrm{nM}$ and 17.5 $\mathrm{nM}$ ), whose linker resembles our $\mathrm{BcO}$ probe. This model required fitting of two dissociation and two association rate constants with the extra equilibrium attributed to two reasons: 1) The interference of the dye structures into the neighboring site due to multiple occupancies on the tetramer ${ }^{58}$ and 2) to possible inhibitory steric interactions caused by high density of SAV sites on 
the surface of the polystyrene particles. Interestingly, a similar model was used to analyze a pulloff study carried out by Scanning Force Microscopy for AV-B complex with immobilized AV in which two events of 20-40 pico-newtons and 40-80 pico-newtons were assigned to the presence of an intermediated. ${ }^{68}$ Categorically, we have avoided these experimental complications by following the reaction at pseudo first order to ensure that our probes occupied only one binding site of AV and SAV in solution (non-immobilized), as discussed above. However, when considering a particular AV or SAV bioassay, one must consider that surface matrix complexity and multiple orientation of the $\mathrm{B}_{7}$ and $\mathrm{AV}$-like proteins can modify the dissociation mechanism with respect to those observed in solution by us.

3.8.2 Reaction model of biotin-DNA ${ }_{d s}$ *Fl binding to $A V$ and $S A V$ was best described by two parallel reactions (Eqn. 9) with two independent association rate constants that showed no evidence of intermediates in solution and whose pre-exponentials were temperature dependent (Table 2) indicating the presence of two $B_{7}$ populations with different orientations with respect to the DNA and responsible for the measured $k_{o n 1}$ and $k_{\text {on } 2}$ rate constants. Thus, at $25^{\circ} \mathrm{C}$, the measured value of $k_{\text {on } 1}$ for both AV and SAV were 20-40\% slower than rate constants acquired with BFl indicating that biotin on the DNA was positioned in a favorable orientation that enhance the reaction. On the other hand, the slower $\mathrm{k}_{\mathrm{on} 2}$ rate constant is associated with an unfavorable orientation of the second $\mathrm{B}_{7}$ population.

3.9 Thermodynamic Parameters: The forward activation energies $\left(\mathrm{E}_{\mathrm{a}}^{\text {forward }}\right.$ or $\Delta \mathrm{H}^{\ddagger}$,forward $)$ of the $\mathrm{B}_{7}$ binding to $\mathrm{AV}$ and $\mathrm{SAV}$ were $\sim 6.0$ and $\sim 14 \mathrm{kcal} / \mathrm{mol}$, respectively; and they were in good agreement with early estimation of $10-12 \mathrm{kcal} / \mathrm{mol}$ for the displacement of water molecules from the binding pocket. ${ }^{57}$ These values were larger than the $3-4 \mathrm{kcal} / \mathrm{mol}^{32,69}$ characteristic of a diffusion limited reaction (which requires also association rate constants in the order of $10^{9} \mathrm{M}^{-1} \mathrm{~s}^{-1}$ 
and our fastest values were in the order of $\sim 1.9 \times 10^{7} \mathrm{M}^{-1} \mathrm{~s}^{-1}$ and $\sim 7.5 \times 10^{7} \mathrm{M}^{-1} \mathrm{~s}^{-1}$, at $25{ }^{\circ} \mathrm{C}$ for AV$\mathrm{BFl}$ and $\mathrm{SAV}-\mathrm{BFl}$, respectively). Hence, the association reaction is not diffusion controlled in the range of experimental work carried by us. Interestingly, the $\mathrm{B}_{7}$ binding process for both proteins share the same $\mathrm{k}_{\mathrm{on}}$ at $52.1{ }^{\circ} \mathrm{C}$ (calculated by Arrhenius plot), and mainly that the binding of $\mathrm{B}_{7}$ ligand enhances thermal stability of the proteins shifting from $75^{\circ} \mathrm{C}$ to $112^{\circ} \mathrm{C}$ for $\mathrm{SAV}$ and from $84{ }^{\circ} \mathrm{C}$ to $117^{\circ} \mathrm{C}$ for $\mathrm{AV} .{ }^{70}$

Remarkably, the difference of forward and reverse activation energies $\left(E_{a}^{\text {forward }}-E_{a}{ }^{\text {backward }}\right.$, calculated with Arrhenius plots of the association and dissociation rate constants, respectively; matched, within the error, the reaction enthalpy $\left(\Delta \mathrm{H}_{\mathrm{Rxn}}^{\circ}\right)$ calculated by calorimetry (Table 3 , Figure $10 \mathrm{~A})$. The same argument holds for entropy $\left(\Delta S^{\ddagger}\right.$, forward $-\Delta S^{\ddagger}$, backwards $)$ and Gibbs free energy $\left(\Delta \mathrm{G}^{\ddagger}\right.$, forward $-\Delta \mathrm{G}^{\ddagger}$, backwards) and the calorimetric $\Delta \mathrm{S}^{\circ}{ }_{\mathrm{Rxn}}$ and $\Delta \mathrm{G}^{\circ}{ }_{\mathrm{Rxn}}$ values calculated by others (see references in Table 3, Figure $10 \mathrm{~B}, \mathrm{C}$ ); Thus, the forward thermodynamic parameters obtained in this study completed nicely the thermodynamics cycles, thus making very compelling arguments in favor of the proposed simple reaction model (Eqn. 8), which has single transition state $\left(^{\ddagger}\right)$ but no intermediate. The positive nature of $\Delta \mathrm{E}_{\mathrm{a}}^{\text {forward }}$ and $\Delta \mathrm{S}$, forward toward the transition state can be explained as the energy required to remove water molecules and displace the protein's $\beta 3-\beta 4$ loop ${ }^{29,71}$ with an increment of the overall disorder, $\Delta \mathrm{S}^{\ddagger}$. A comparative analysis of the transition state $\left({ }^{\ddagger}\right)$ for the AV-B and SAV-B complexes reveals that the former has a larger $\Delta \mathrm{E}_{\mathrm{a}}^{\text {forward }}$ and $\Delta \mathrm{S}^{\ddagger}$,forward (Table 3, Figure 10, red line) than the latter (Table 3, Figure 10, green line) which implies that binding sites of $\mathrm{AV}$ are deeper and less accessible resulting in a slower association rate constants, $\mathrm{k}_{\mathrm{on}}$, and larger activation energy with respect to biotin binding to SAV.

The fluorescence spectroscopic parameters. The absorbance and emission peaks of all the dyelabeled $\mathrm{B}_{7}$ complexes (Table 4) were red shifted a few nanometers (Supporting Information, Figure 
$\mathrm{S} 1$ and S2) with respect to the unbound probes, with the exception of the biotin-DNA ${ }_{\mathrm{ds}} * \mathrm{~F} 1$ complexes with AV and SAV that were blue-shifted $3 \mathrm{~nm}$ by the presence of both proteins. This can be explained due to fluorescein (Fl) interactions with $\mathrm{DNA}_{\mathrm{ds}}$ before binding to AV and SAV and later displaced toward the solution in the complex. In the particular case of the absorbance spectrum of SAV-BF1, it was highly distorted (Supporting Information, Figure S1 B) owing to the shifting of the $\mathrm{Fl}^{-2} / \mathrm{Fl}^{-1}$ equilibrium by charge transfer; ${ }^{72}$ since, we detected the corresponding 4.1 ns and $3.0 \mathrm{~ns}$ lifetimes $(\tau)$. The time-resolved fluorescence of biotin-DNA ${ }_{\mathrm{ds}}{ }^{*} \mathrm{Fl}$ complexes of both proteins (Supporting Information, Table S3) had two lifetimes decays whose exponentials were not affected by temperature suggesting the existence of the two Fl positions on the DNA which make a compelling argument for the parallel reaction model (Eqn. 9) with two reacting populations: $\left(\text { Biotin-DNA }_{d s}{ }^{*} \mathrm{Fl}\right)_{1}$ and $\left(\text { Biotin-DNA }_{d s}{ }^{*} \mathrm{Fl}\right)_{2}$,

The deconvolution of the SF binding traces was completed using the steady-state anisotropy $\left(\mathrm{r}_{\mathrm{ss}}\right)$ whose AV values were larger than SAV attributable to a larger molecular weight and to the presence of the carbohydrate motif for the former. Significantly, the quantum yields (QY) of the complexes were in excellent agreement with all the binding association traces, which is particularly important for the biotin-DNA ${ }_{\mathrm{ds}} * \mathrm{Fl}$ reactions, whose traces had shifted directions (Figure 7) owing to opposite quenching interactions from the initial quantum yield, QY=0.22 \pm 0.01 , of the free probe biotin- $\mathrm{DNA}_{\mathrm{ds}} * \mathrm{Fl}$ (Table 4) to an increment up to $0.36 \pm 0.01$ for the AVbiotin-DNA $\mathrm{ds}^{*} \mathrm{~F} 1$ complex and a decrement to $0.18 \pm 0.01$ for the SAV-biotin-DNA ${ }_{\mathrm{ds}} * \mathrm{~F} 1$ complex. This effect is caused by the bulker nature of the AV with respect to SAV that allows further displacement of $\mathrm{Fl}$ from the 3 ' end toward the solution environment resulting in the increase of the QY for the biotin-DNA ${ }_{\mathrm{ds}}^{*} \mathrm{Fl}-\mathrm{AV}$. 
The (S) and (1-S) are, respectively, the emitting and statically quenched dye populations. The latter always increased with the complex formation with respect to the unbound free probes; thus, the fluorescence information pertained to the self-revealing population whose cone angles $(\Omega)$ of $\sim 50^{\circ}$ pointed out that the dye probe was fairly free to rotate (Figure 11 ) in the complexes. On the other hand, the presence of (1-S) did not affect the accuracy of association rate values, as the rates obtained in the independent SAV tryptophan-quenching study ${ }^{36}$ and our data were in perfect agreement.

\section{CONCLUSIONS.}

In the presented study, we calculated the association rate constants of $\mathrm{B}_{7}$ binding to $\mathrm{AV}$ and $\mathrm{SAV}$ with dye-labeled $\mathrm{B}_{7}$ probes and unlabeled $\mathrm{B}_{7}$. We concluded that attached fluorescent probes did not alter the association rates and no binding cooperativity was observed when comparing the initial (unoccupied) and final (occupied) binding rates. The fluorescence, $\bar{F}(t)$, and corrected anisotropy signals, $\overline{r F}(t)$, of the dye-labeled $\mathrm{B}_{7}$ probes provided truthful binding traces contrary to the uncorrected anisotropy signal, $\bar{r}(t)$, due to changes in the QY of the participating reacting species. The $\mathrm{B}_{7}$ association rate constants of SAV are several times faster than AV and the glycan chain of the latter does not play a role in the $\mathrm{B}_{7}$ binding association and neither explains the difference in the $\mathrm{k}_{\text {on }}$ values between these two proteins. Thus, we conclude that the main differences in reaction speeds is likely related to structural aspects of the binding sites. A deeper pocket in AV would be filled with more water molecules requiring more energy to break the hydrogen bonds. Also, the variation in requirements for induced fit could explain in larger activation energy and entropic increment for AV compared to the SAV in the overall thermodynamics of the reaction. Interestingly, the overall reaction free energy changes are equivalent. 
The association rate constant for $\mathrm{BcO}$, in which the tag is attached to a longer linker of biocytin, is $\sim 2 \mathrm{X}$ faster than $\mathrm{B}_{7}$ with the shorter linker $(\mathrm{BFl})$ for both proteins. The difference of $100 \mathrm{X}$ in $\mathrm{K}_{\mathrm{D}}$ of AV complex with biotin and biocytin can be explained by differences in the dissociation process rather than the association rate constants. The $\mathrm{B}_{7}$ binding to AV and SAV is not diffusion limited as larger than $3 \mathrm{kcal} / \mathrm{mol}$ activation energies were calculated with Arrhenius plots of the rate constants, and those all of those rates were two orders of magnitude slower (on average $\sim 10^{7} \mathrm{M}^{-}$ ${ }^{1} \mathrm{~S}^{-1}$ ) than the $10^{9} \mathrm{M}^{-1} \mathrm{~S}^{-1}$ required for diffusion limited reactions. The forward thermodynamic parameters of $\mathrm{B}_{7}$ binding to $\mathrm{AV}$ and $\mathrm{SAV}$ complemented nicely the thermodynamic cycles with data obtained with independent calorimetric studies and dissociation kinetics elsewhere. Thus, the most probable reaction model is the one with non-intermediate and a single transition state in solution but it could be more elaborate on support matrices, such as chips.

The spectroscopic properties indicated very compact complexes with high dye mobility for all the probes, $\mathrm{BFl}, \mathrm{BcO}$ and biotin- $\mathrm{DNA}_{\mathrm{ds}} * \mathrm{Fl}$. We report for the first time a bimolecular displacement process for the $\mathrm{SAV}-\mathrm{BcO}$ complex when challenged by unlabeled $\mathrm{B}_{7}$ and this displacement rate constant for the $\mathrm{B}_{7}$ with the longer linker (biocytin) in the $\mathrm{BcO}$ suggests that repair and recondition of enriched biotin-avidin-like surfaces is possible if even long linkers are used. A potential application of dye-labeled $\mathrm{B}_{7}$ and AV-like complex could be in Dye- Sensitized Solar Cells $(\mathrm{DSSC})^{73,74}$ as the AV and SAV complexes are highly thermally stable at $112^{\circ} \mathrm{C}$ and $117^{\circ} \mathrm{C}^{70}$, respectively, may perhaps be attached covalently to the n-type material (e.g. $\mathrm{TiO}_{2}$ ) and the chargetransfer molecule to B; e.g. porphyrins, chlorophylls, ruthenium-complexes, coumarins or indoline dyes, ${ }^{75}$ with the advantage of regeneration capabilities, as damage dye can be reconditioned or replaced by another dye type on the tetramer attached surface (Figure 9A). The spectroscopic properties of these dye-labeled $\mathrm{B}_{7}$ and $\mathrm{AV}$-like complexes are vital for detection methods based 
on polarization, fluorescence, anisotropy and Fluorescence Resonance Energy Transfer (FRET) systems because static, dynamic quenching and rotational constrains of the fluorescent probes reduce the detection limits by decreasing the signal to noise ratios. ${ }^{76}$ and producing artifacts. The information in here presented will be valuable to improve new nano-technological applications of $\mathrm{B}_{7}$ and $\mathrm{AV}$-like protein systems.

ASSOCIATED CONTENT: Supporting Information Available: "Displacement reaction of SAV-BFl by unlabeled B, absorbance and emission spectra of dye-labeled $\mathrm{B}_{7}$ complexes, and fluorescence lifetime table". The following files are available free of charge.

Figure S1. Absorbance spectra of dye-labeled biotin probes (PDF).

Figure S2. Fluorescence emission spectra of dye-labeled biotin probes (PDF).

Table S3. Lifetimes of dye-labeled biotin probes and protein complexes (PDF).

\section{Funding Sources.}

The work was supported by: National Institutes of Health Grants GM59346 and RR015468 to LJP; CONACYT-Mexico postdoctoral, SNI fellowships (130994, 162809, SNI75487) and the Government of Veracruz-Mexico gifted-student fellowships to RFD; Bioengineering, Biosystems and Synthetic Biology Focus Group of Tecnológico de Monterrey (002EICIP01).

ACKNOWLEDGMENT: This work was carried out at Department of Chemistry, University of Nebraska-Lincoln, NE 68588-0304, USA. Roberto F Delgadillo thanks Dr. Efrain Barragan, Dr. Omar Olmos-Lopez and Ms. Lola R. for their support; Andrea R. Gomez-Fernandez and Yuriana Oropeza for proof reading the manuscript; CONACYT-Mexico for the postdoctoral and SNI grants; and the Government of Veracruz-Mexico. Roberto F. Delgadillo and José González-Valdez 
would like to thank the Bioengineering, Biosystems and Synthetic Biology Focus Group of

Tecnológico de Monterrey (002EICIP01) for its support.

\section{REFERENCES}

(1) Wilchek, M., and Bayer, E. A. (1990) Introduction to avidin-biotin technology. Methods Enzymol. 184, 5-13.

(2) Wilchek, M. (2004) My life with affinity. Protein Sci. 11, 3066-70.

(3) Bayer, E. A., and Wilchek, M. (1980) The Use of the Avidin-Biotin Complex as a Tool in Molecular Biology. Methods Biochem. Anal. 26, 1-45.

(4) Diamandis, E. P., and Christopoulos, T. K. (1991) The biotin-(strept)avidin system: principles and applications in biotechnology. Clin. Chem. 37, 625-636.

(5) Wilchek, M., and Bayer, E. A. (1984) The avidin-biotin complex in immunology. Immunol. Today 5, 39-43.

(6) Orth, R. N., Clark, T. G., and Craighead, H. G. (2003) Avidin-Biotin Micropatterning Methods for Biosensor Applications. Biomed. Microdevices 5, 29-34.

(7) Park, K. M., Murray, J., and Kim, K. (2017) Ultrastable artificial binding pairs as a supramolecular latching system: A next generation chemical tool for proteomics. Acc. Chem. Res. $50,644-646$.

(8) Jurinke, C., Van den Boom, D., Collazo, V., Lüchow, A., Jacob, A., and Köster, H. (1997) Recovery of Nucleic Acids from Immobilized Biotin-Streptavidin Complexes Using Ammonium Hydroxide and Applications in MALDI-Tof Mass Spectrometry. Anal. Chem. 69, 904-910. 
(9) Michalet, X., Pinaud, F. F., Bentolila, L. A., Tsay, J. M., Doose, S., Li, J. J., Sundaresan, G., Wu, A. M., Gambhir, S. S., and Weiss, S. (2005) Quantum dots for live cells, in vivo imaging, and diagnostics. Science 307, 538-44.

(10) Howarth, M., and Ting, A. Y. (2008) Imaging proteins in live mammalian cells with biotin ligase and monovalent streptavidin. Nat. Protoc. 3, 534-545.

(11) Jain, A., and Cheng, K. (2017) The principles and applications of avidin-based nanoparticles in drug delivery and diagnosis. J. Control. Release 245, 27-40.

(12) Förster, T., Energiewanderung, Z., and Von, F. (1939) Zwischenmolekulare Energiewanderung und Fluoreszenz. Ann. Phys.

(13) Bazin, Préaudat, Trinquet, and Mathis. (2001) Homogeneous time resolved fluorescence resonance energy transfer using rare earth cryptates as a tool for probing molecular interactions in biology. Spectrochim. acta Part A, Mol. Biomol. Spectrosc. 57, 2197-2211.

(14) Cisbio. (2016) HTRF Glucagon Kit Protocol. Cisbio Appl. Note.

(15) Nørskov-Lauritsen, L., Thomsen, A. R. B., and Bräuner-Osborne, H. (2014) G proteincoupled receptor signaling analysis using homogenous time-resolved Förster resonance energy transfer (HTRF®) technology. Int. J. Mol. Sci.

(16) Morpurgo, M., Radu, A., Bayer, E. A., and Wilchek, M. (2004) DNA condensation by highaffinity interaction with avidin. J. Mol. Recognit. 17, 558-566.

(17) Kramer, K. J., Morgan, T. D., Throne, J. E., Dowell, F. E., Bailey, M., and Howard, J. A. (2000) Transgenic avidin maize is resistant to storage insect pests. Nat. Biotechnol. 18, 670-674. 
(18) Helppolainen, S. H., Nurminen, K. P., Määttä, J. a E., Halling, K. K., Slotte, J. P., Huhtala, T., Liimatainen, T., Ylä-Herttuala, S., Airenne, K. J., Närvänen, A., Jänis, J., Vainiotalo, P., Valjakka, J., Kulomaa, M. S., and Nordlund, H. R. (2007) Rhizavidin from Rhizobium etli: the first natural dimer in the avidin protein family. Biochem. J. 405, 397-405.

(19) Meir, A., Helppolainen, S. H., Podoly, E., Nordlund, H. R., Hytönen, V. P., Määttä, J. A., Wilchek, M., Bayer, E. A., Kulomaa, M. S., and Livnah, O. (2009) Crystal Structure of Rhizavidin: Insights into the Enigmatic High-Affinity Interaction of an Innate Biotin-Binding Protein Dimer. J. Mol. Biol. 386, 379-390.

(20) Takakura, Y., Tsunashima, M., Suzuki, J., Usami, S., Kakuta, Y., Okino, N., Ito, M., and Yamamoto, T. (2009) Tamavidins - Novel avidin-like biotin-binding proteins from the Tamogitake mushroom. FEBS J. 276, 1383-1397.

(21) Määttä, J. A., Helppolainen, S. H., Hytönen, V. P., Johnson, M. S., Kulomaa, M. S., Airenne, T. T., and Nordlund, H. R. (2009) Structural and functional characteristics of xenavidin, the first frog avidin from Xenopus tropicalis. BMC Struct. Biol. 9.

(22) Helppolainen, S. H., Määttä, J. A. E., Halling, K. K., Slotte, J. P., Hytönen, V. P., Jänis, J., Vainiotalo, P., Kulomaa, M. S., and Nordlund, H. R. (2008) Bradavidin II from Bradyrhizobium japonicum: A new avidin-like biotin-binding protein. Biochim. Biophys. Acta - Proteins Proteomics 1784, 1002-1010.

(23) Nordlund, H. R., Hytönen, V. P., Laitinen, O. H., and Kulomaa, M. S. (2005) Novel avidinlike protein from a root nodule symbiotic bacterium, Bradyrhizobium japonicum. J. Biol. Chem. $280,13250-13255$. 
(24) Keinänen, R. A., Wallén, M. J., Kristo, P. A., Laukkanen, M. O., Toimela, T. A., Helenius, M. A., and Kulomaa, M. S. (1994) Molecular cloning and nucleotide sequence of chicken avidin-related genes 1-5. Eur. J. Biochem. 220, 615-621.

(25) Hytönen, V. P., Määttä, J. A. E., Kidron, H., Halling, K. K., Hörhä, J., Kulomaa, T., Nyholm, T. K. M., Johnson, M. S., Salminen, T. A., Kulomaa, M. S., and Airenne, T. T. (2005) Avidin related protein 2 shows unique structural and functional features among the avidin protein family. BMC Biotechnol. 5.

(26) Prizant, M., Eisenberg-Domovich, Y., Hytönen, V. P., Kulomaa, M. S., Wilchek, M., Bayer, E. A., and Livnah, O. (2006) Factors Dictating the Pseudocatalytic Efficiency of Avidins. J. Mol. Biol. 358, 754-763.

(27) Huberman, T., Eisenberg-Domovich, Y., Gitlin, G., Kulik, T., Bayer, E. A., Wilchek, M., and Livnah, O. (2001) Chicken avidin exhibits pseudo-catalytic properties. Biochemical, structural, and electrostatic consequences. J. Biol. Chem. 276, 32031-32039.

(28) Hayouka, R., Eisenberg-Domovich, Y., Hytönen, V. P., Määttä, J. A. E., Nordlund, H. R., Kulomaa, M. S., Wilchek, M., Bayer, E. A., and Livnah, O. (2008) Critical importance of loop conformation to avidin-enhanced hydrolysis of an active biotin ester. Acta Crystallogr. Sect. D Biol. Crystallogr. 64, 302-308.

(29) Livnah, O., Bayer, E. A., Wilchek, M., and Sussman, J. L. (1993) Three-dimensional structures of avidin and the avidin-biotin complex. Proc. Natl. Acad. Sci. 90, 5076-5080.

(30) Donovan, J. W., and Ross, K. D. (1973) Increase in the Stability of Avidin Produced by Binding of Biotin. a Differential Scanning Calorimetric Study of Denaturation by Heat. 
Biochemistry.

(31) Laitinen, O. H., Nordlund, H. R., Hytönen, V. P., Uotila, S. T. H., Marttila, A. T., Savolainen, J., Airenne, K. J., Livnah, O., Bayer, E. A., Wilchek, M., and Kulomaa, M. S. (2003) Rational design of an active avidin monomer. J. Biol. Chem.

(32) Green, N. M. (1963) The use of [14C]biotin for kinetic studies and for assay. Biochem. J. 89, 585-91.

(33) Wayment, J. R., and Harris, J. M. (2009) Biotin-avidin binding kinetics measured by singlemolecule imaging. Anal. Chem. 81, 336-342.

(34) Srisa-Art, M., DeMello, A. J., and Edel, J. B. (2007) High-throughput DNA droplet assays using picoliter reactor volumes. Anal. Chem. 79, 6682-6689.

(35) Srisa-Art, M., Dyson, E. C., DeMello, A. J., and Edel, J. B. (2008) Monitoring of real-time streptavidin-biotin binding kinetics using droplet microfluidics. Anal. Chem. 80, 7063-7067.

(36) Hyre, D. E., Le Trong, I., Merritt, E. A., Eccleston, J. F., Green, N. M., Stenkamp, R. E., and Stayton, P. S. (2006) Cooperative hydrogen bond interactions in the streptavidin-biotin system. Protein Sci. 15, 459-67.

(37) Green, N. M. (1970) Spectrophotometric Determination of Avidin and Biotin. Methods Enzymol. 18, 418-424.

(38) Livnah, O., Bayer, E. A., Wilchek, M., and Sussman, J. L. (1993) The structure of the complex between avidin and the dye, 2-(4'-hydroxyazobenzene) benzoic acid (HABA). FEBS Lett. 328, 165-168. 
(39) Delgadillo, R. F., Whittington, J. D. E., Parkhurst, L. K., and Parkhurst, L. J. (2009) The TATA-binding protein core domain in solution variably bends TATA sequences via a three-step binding mechanism. Biochemistry 48, 1801-1809.

(40) Pihan, E., Delgadillo, R. F., Tonkin, M. L., Pugnière, M., Lebrun, M., Boulanger, M. J., and Douguet, D. (2015) Computational and biophysical approaches to protein-protein interaction inhibition of Plasmodium falciparum AMA1/RON2 complex. J. Comput. Aided. Mol. Des. 29, $525-539$.

(41) Whittington, J. D. E., Delgadillo, R. F., Attebury, T. J., Parkhurst, L. K., Daugherty, M. A., and Parkhurst, L. J. (2008) TATA-binding protein recognition and bending of a consensus promoter are protein species dependent. Biochemistry 47, 7264-7273.

(42) Delgadillo, R. F., Parker, M. L., Lebrun, M., Boulanger, M. J., and Douguet, D. (2016) Stability of the Plasmodium falciparum AMA1-RON2 Complex Is Governed by the Domain II (DII) Loop. PLoS One 11.

(43) Delgadillo, R. F., and Parkhurst, L. J. (2010) Spectroscopic properties of fluorescein and rhodamine dyes attached to DNA. Photochem. Photobiol. 86, 261-272.

(44) Hytönen, V. P., Määttä, J. A. E., Niskanen, E. A., Huuskonen, J., Helttunen, K. J., Halling, K. K., Nordlund, H. R., Rissanen, K., Johnson, M. S., Salminen, T. A., Kulomaa, M. S., Laitinen, O. H., and Airenne, T. T. (2007) Structure and characterization of a novel chicken biotin-binding protein A (BBP-A). BMC Struct. Biol. 7.

(45) Giblin, D. E. (1978) A modular instrument for the measurement of transient circular dichroism, fluorescence polarization and emission anisotropy. University of Nebraska-Lincoln. 
(46) Parker, C. A., and Rees, W. T. (1960) Correction of fluorescence spectra and measurement of fluorescence quantum efficiency. Analyst 85, 587.

(47) Crosby, G. A., and Demas, J. N. (1971) Measurement of photoluminescence quantum yields. Review. J. Phys. Chem. 75, 991-1024.

(48) Mueser, T. C. (1989) Steady state fluorescence and fluorescence anisotropy studies of ligand binding and kinetics. University of Nebraska-Lincoln.

(49) Foss, S. D. (1970) A Method of Exponential Curve Fitting by Numerical Integration. Biometrics 26, 815-821.

(50) Görisch, H., Goss, D. J., and Parkhurs, L. J. (1976) Kinetics of Ribosome Dissociation and Subunit Association Studied in a Light-Scattering Stopped-Flow Apparatus. Biochemistry 15, $5743-5753$.

(51) Parkhurst, K. M., Brenowitz, M., and Parkhurst, L. J. (1996) Simultaneous binding and bending of promoter DNA by the TATA binding protein: Real time kinetic measurements. Biochemistry 35, 7459-7465.

(52) Otto, M. R., Lillo, M. P., and Beechem, J. M. (1994) Resolution of multiphasic reactions by the combination of fluorescence total-intensity and anisotropy stopped-flow kinetic experiments. Biophys. J. 67, 2511-2521.

(53) Bucci, E., and Steiner, R. F. (1988) Anisotropy decay of fluorescence as an experimental approach to protein dynamics. Biophys. Chem. 30, 199-224.

(54) Cantor, C. R., and Schimmel, P. R. (1980) Techniques for the Study of Biological Structure and Function (Pt. 2). Biophys. Chem. First. W.H. Freeman and Company, San Francisco. 
(55) Parkhurst, L. J., Parkhurst, K. M., Powell, R., Wu, J., and Williams, S. (2002) Time-resolved fluorescence resonance energy transfer studies of DNA bending in double-stranded oligonucleotides and in DNA-protein complexes. Biopolymers 61, 180-200.

(56) Lipari, G., and Szabo, A. (1980) Effect of librational motion on fluorescence depolarization and nuclear magnetic resonance relaxation in macromolecules and membranes. Biophys. J. 30, 489-506.

(57) GREEN, N. M. (1963) AVIDIN. 3. THE NATURE OF THE BIOTIN-BINDING SiTE. Biochem. J. 89, 599-609.

(58) Sinha, B. K., and Chignell, C. F. (1979) The synthesis and use of spin-labeled analogs of biotin in the study of avidin. Methods Enzymol. 62, 295-308.

(59) Bayer, E. A., and Wilchek, M. (1990) Biotin-binding Proteins: Overview and Prospects. Methods Enzymol. 184, 49-51.

(60) Perutz, M. F., Ladner, J. E., Simon, S. R., and Chien, H. (1974) Influence of globin structure on the state of the heme. I. Human deoxyhemoglobin. Biochemistry 13, 2163-2173.

(61) Parkhurst, L. J., Goss, D. J., Perutz, M. F., Parkhurst, L. J., Goss, D. J., and Perutz, M. F. (1983) Kinetic and Equilibrium Studies on the Role of the $\beta-147$ Histidine in the Root Effect and Cooperativity in Carp Hemoglobin. Biochemistry 22, 5401-5409.

(62) Hiller, Y., Gershoni, J. M., Bayer, E. A., and Wilchek, M. (1987) Biotin binding to avidin. Oligosaccharide side chain not required for ligand association. Biochem. J. 248, 167-71.

(63) Qureshi, M. H., Yeung, J. C., Wu, S. C., and Wong, S. L. (2001) Development and Characterization of a Series of Soluble Tetrameric and Monomeric Streptavidin Muteins with 
Differential Biotin Binding Affinities. J. Biol. Chem. 276, 46422-46428.

(64) John W. Moore, R. G. P. (1981) Kinetics and Mechanism. Third. Wiley Interscience.

(65) Piran, U., and Riordan, W. J. (1990) Dissociation rate constant of the biotin-streptavidin complex. J. Immunol. Methods 133, 141-143.

(66) Buranda, T., Jones, G. M., Nolan, J. P., Keij, J., Lopez, G. P., and Sklar, L. A. (1999) Ligand Receptor Dynamics at Streptavidin-Coated Particle Surfaces: A Flow Cytometric and Spectrofluorimetric Study. J. Phys. Chem. B 103, 3399-3410.

(67) Wu, Y., Simons, P. C., Lopez, G. P., Sklar, L. A., and Buranda, T. (2005) Dynamics of fluorescence dequenching of ostrich-quenched fluorescein biotin: A multifunctional quantitative assay for biotin. Anal. Biochem. 342, 221-228.

(68) De Paris, R., Strunz, T., Oroszlan, K., Güntherodt, H.-J., and Hegner, M. (2000) Force Spectroscopy and Dynamics of the BiotinAvidin Bond Studied by Scanning Force Microscopy. Single Mol. 1, 285-290.

(69) Connors, K. A. (1990) Chemical Kinetics: The Study of Reaction Rates in Solution. VCH Publishers, Inc, New York.

(70) González, M., Argaraña, C. E., and Fidelio, G. D. (1999) Extremely high thermal stability of streptavidin and avidin upon biotin binding. Biomol. Eng. 16, 67-72.

(71) Celej, M. S., Montich, G. G., and Fidelio, G. D. (2004) Conformational flexibility of avidin: The influence of biotin binding. Biochem. Biophys. Res. Commun. 325, 922-927.

(72) Waner, M. J., and Mascotti, D. P. (2008) A simple spectrophotometric streptavidin-biotin 
binding assay utilizing biotin-4-fluorescein. J. Biochem. Biophys. Methods 70, 873-877.

(73) Oregan, B., and Gratzel, M. (1991) A Low-cost, High-efficiency Solar Cell Based on Dyesensitized Colloidal TiO2 Films. Nature 353, 737-740.

(74) McGehee, M. D. (2011) Applied physics. Paradigm shifts in dye-sensitized solar cells. Science 334, 607-8.

(75) Ito, S. (2011) Investigation of Dyes for Dye-Sensitized Solar Cells: Ruthenium-Complex Dyes, Metal-Free Dyes, Metal-Complex Porphyrin Dyes and Natural Dyes. InTech 20-48.

(76) Lakowicz, J. R. (2006) Principles of fluorescence spectroscopy. Princ. Fluoresc. Spectrosc.

(77) Green, N. (1966) Thermodynamics of the binding of biotin and some analogues by avidin. Biochem. J. 101, 774-780.

(78) Stjurkuusk, J., and Wadso, I. (1972) Thermochemistry of the Avidin-Biotin Reaction Calorimetric Equipment and Procedure For the protein-binding experiments an LKB. Eur. J. Biochem 28, 438-441.

(79) Swamy, M. J. (1995) Thermodynamic analysis of biotin binding to avidin. A high sensitivity titration calorimetric study. Biochem Mol Biol Int 36, 219-225.

(80) Klumb, L. A., Chu, V., and Stayton, P. S. (1998) Energetic roles of hydrogen bonds at the ureido oxygen binding pocket in the streptavidin-biotin complex. Biochemistry 37, 7657-7663.

(81) Hyre, D. E., Le Trong, I., Freitag, S., Stenkamp, R. E., and Stayton, P. S. (2000) Ser45 plays an important role in managing both the equilibrium and transition state energetics of the streptavidin-biotin system. Protein Sci. 9, 878-885. 
(82) Stayton, P. S., Freitag, S., Klumb, L. A., Chilkoti, A., Chu, V., Penzotti, J. E., To, R., Hyre, D., Le Trong, I., Lybrand, T. P., and Stenkamp, R. E. (1999) Streptavidin-biotin binding energetics. Biomol. Eng. 16, 39-44.

(83) Weber, P. C., Wendoloski, J. J., Pantoliano, M. W., and Salemme, F. R. (1992) Crystallographic and Thermodynamic Comparison of Natural and Synthetic Ligands Bound to Streptavidin. J. Am. Chem. Soc. 114, 3197-3200.

(84) Weber, P. C., Pantoliano, M. W., and Salemme, R. (1995) General Medical Applications of Structure-Aided Design. Acta Cryst D51 590-596.

(85) Sjöback, R., Nygren, J., Kubista, M., Sjback, R., Nygren, J., and Kubista, M. (1995) Absorption and fluorescence properties of fluorescein. Spectrochim. Acta Part A 51, L7-L21.

(86) Sjöback, R., Nygren, J., and Kubista, M. (1998) Characterization of Fluorescein Oligonucleotide Conjugates and Measurement of Local Electrostatic Potential. Biopolymers 46, $445-453$.

(87) Sjoback, R., Nygren, J., and Kubista, M. (1999) Characterization of fluoresceinoligonucleotide conjugates and measurement of local electrostatic potential. Doktorsavhandlingar vid Chalmers Tek. Hogsk. 445-453.

(88) Parkhurst, L. J. (2001) Near-Infrared Applications in Biotechnology. Practical Spectroscopy Series (R. Raghavachari, Ed), pp 5-33. Marcel Dekker, Inc, New York. 
Table 1. Comparison of the association rate constants $\left(\mathrm{k}_{\mathrm{on}}\right)$ obtained by fluorescence change, $\overline{\boldsymbol{F}}(\boldsymbol{t})$, and corrected fluorescence anisotropy, $\overline{\boldsymbol{r} \boldsymbol{F}}(\boldsymbol{t})$, of $\mathrm{BcO}(20 \mathrm{nM})$ binding to $\mathrm{AV}$ at several temperatures, protein concentrations and $\mathrm{pH} 8 .^{\mathrm{a}}$

\begin{tabular}{|c|c|c|c|c|c|c|c|c|c|c|c|}
\hline Complex ${ }^{a}$ & $\begin{array}{c}25^{\circ} \mathrm{C} \\
\left(\times 10^{-6} \mathrm{M}^{-1} \mathrm{~s}^{-1}\right)\end{array}$ & $\begin{array}{c}20^{\circ} \mathrm{C} \\
\left(\times 10^{-6} \mathrm{M}^{-1} \mathrm{~s}^{-1}\right)\end{array}$ & & $\begin{array}{l}5{ }^{\circ} \mathrm{C} \\
\left.{ }^{6} \mathbf{M}^{-1} \mathbf{s}^{-1}\right)\end{array}$ & $\begin{array}{r}1 \\
(\times 10\end{array}$ & $\begin{array}{l}{ }^{\circ} \mathrm{C} \\
\left.{ }^{6} \mathbf{M}^{-1} \mathrm{~s}^{-1}\right)\end{array}$ & & 1/mol) & (cal/ ${ }^{\circ}$ & & $\begin{array}{r}\Delta \mathrm{G}^{+} \\
(\mathrm{kcal} / \mathrm{m}\end{array}$ \\
\hline $\mathrm{k}_{\mathrm{on}}, \mathrm{AV}-\mathrm{BcO}$ & \multicolumn{5}{|c|}{$\overline{\bar{F}}(t), \times 10^{-6} \mathrm{M}^{-1} \mathrm{~s}^{-1}$} & \multicolumn{6}{|c|}{$\overline{r F}(t), \times 10^{-6} M^{-1} s^{-1}$} \\
\hline Temp. & $260 \mathrm{nM}$ & \multicolumn{2}{|c|}{$520 \mathrm{nM}$} & \multicolumn{2}{|c|}{$1040 \mathrm{nM}$} & \multicolumn{2}{|c|}{$260 \mathrm{nM}$} & \multicolumn{2}{|c|}{$520 \mathrm{nM}$} & \multicolumn{2}{|c|}{$1040 \mathrm{nM}$} \\
\hline $25^{\circ} \mathrm{C}$ & $9.5 \pm 0.1$ & \multicolumn{2}{|c|}{$9.5 \pm 0.3$} & \multicolumn{2}{|c|}{$9.7 \pm 0.3$} & \multicolumn{2}{|c|}{$9.5 \pm 0.1$} & \multicolumn{2}{|c|}{$9.5 \pm 0.1$} & \multicolumn{2}{|c|}{$9.4 \pm 0.2$} \\
\hline $20^{\circ} \mathrm{C}$ & $5.7 \pm 0.1$ & \multicolumn{2}{|c|}{$5.9 \pm 0.3$} & \multicolumn{2}{|c|}{$6.0 \pm 0.1$} & \multicolumn{2}{|c|}{$5.9 \pm 0.1$} & \multicolumn{2}{|c|}{$5.8 \pm 0.1$} & \multicolumn{2}{|c|}{$6.1 \pm 0.1$} \\
\hline $15^{\circ} \mathrm{C}$ & $4.1 \pm 0.1$ & \multicolumn{2}{|c|}{$3.95 \pm 0.1$} & \multicolumn{2}{|c|}{$3.9 \pm 0.2$} & \multicolumn{2}{|c|}{$4.0 \pm 0.1$} & \multicolumn{2}{|c|}{$3.82 \pm 0.1$} & \multicolumn{2}{|c|}{$4.0 \pm 0.2$} \\
\hline $10{ }^{\circ} \mathrm{C}$ & $2.4 \pm 0.1$ & \multicolumn{2}{|c|}{$2.6 \pm 0.2$} & \multicolumn{2}{|c|}{$2.5 \pm 0.2$} & \multicolumn{2}{|c|}{$2.7 \pm 0.1$} & \multicolumn{2}{|c|}{$2.7 \pm 0.1$} & \multicolumn{2}{|c|}{$2.7 \pm 0.1$} \\
\hline
\end{tabular}

aThe $\overline{\boldsymbol{F}}(\boldsymbol{t})$ and $\overline{\boldsymbol{r} F}(\boldsymbol{t})$ signals were equivalent as they tracked in the errors the association process of dye-labeled $\mathrm{B}_{7}$ binding to the proteins under pseudo first order conditions. 


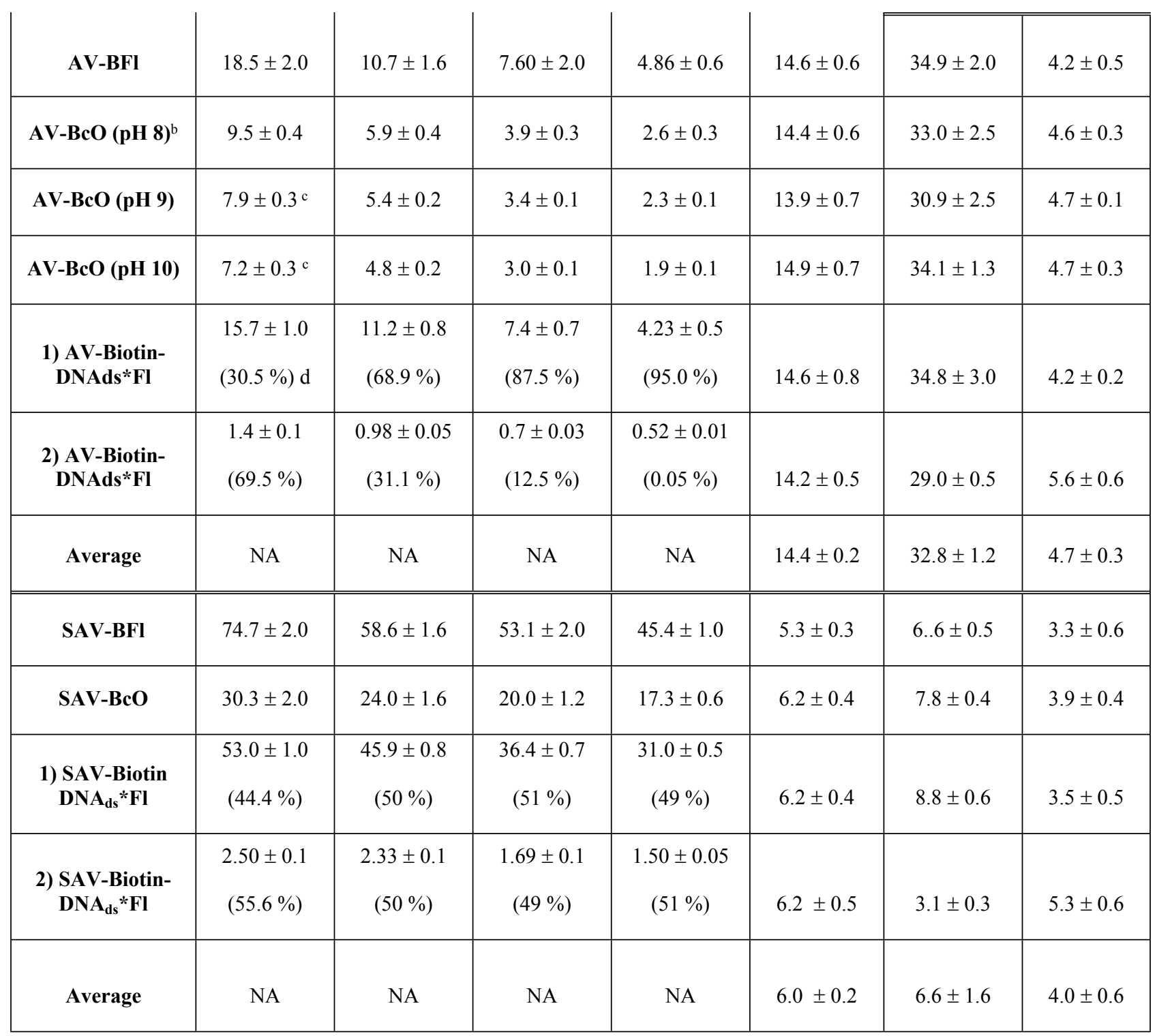

Table 2. Association rate constants $\left(\mathrm{k}_{\mathrm{on}}\right)$ and thermodynamic values of the dye-labeled biotin binding to AV and SAV.

aThe probes were $\mathrm{BFl}, \mathrm{BcO}$, and biotin attached to a nucleotide in a 14-mer DNA duplex. The thermodynamic values were acquired from global fitting of the rate constants ${ }^{39,42}$ for the most probable model which resulted in simple reaction with a transition state without intermediates. In case of biotin-DNA duplex, the reaction model was a two-serial reaction model also with one transition state without intermediates. The nature of the serial reaction is probably caused by two $\mathrm{B}_{7}$ populations with different spatial orientation.

${ }^{b}$ The $\mathrm{k}_{\mathrm{on}}$ were averaged from data in Table 1

${ }^{c}$ Calculated from an Arrhenius plot. 
bioRxiv preprint doi: https://doi.org/10.1101/410548; this version posted September 6,2018 . The copyright holder for this preprint (which was not certified by peer review) is the author/funder, who has granted bioRxiv a license to display the preprint in perpetuity. It is made available under aCC-BY 4.0 International license.

${ }^{d}$ The pre-exponentials (in parenthesis) of $\mathrm{k}_{\mathrm{on} 1}$ and $\mathrm{k}_{\mathrm{on} 2}$ were renormalized after removing a third process associated to remaining photobleaching. 
Table 3. Thermodynamic cycles of biotin binding to AV and SAV for one transition state. ${ }^{\mathrm{a}}$

\begin{tabular}{|c|c|c|c|c|}
\hline Complex & $\begin{array}{c}\Delta H^{\circ} \mathbf{r x n} \\
(\mathrm{kcal} / \mathrm{mol})\end{array}$ & $\begin{array}{l}\text { Ea forwards } \\
(\mathrm{kcal} / \mathrm{mol})\end{array}$ & $\begin{array}{l}\text { Ea backwards } \\
(\mathrm{kcal} / \mathrm{mol})\end{array}$ & $\begin{array}{c}\Delta \mathbf{E}=\mathbf{E a}_{\text {forward }}-\mathbf{E a}_{\text {backwards }} \\
{(\mathrm{kcal} / \mathrm{mol})^{b}}^{b}\end{array}$ \\
\hline$A V-B$ & $\begin{array}{l}-20.3 \pm 0.3^{77} \\
-22.5 \pm 0.1^{78} \\
-26.7^{36} \\
-23.4 \pm 0.3^{79} \\
-23.2 \pm 1.7^{c}\end{array}$ & $14.4 \pm 0.2$ & $37.6 \pm 2.0^{18}$ & $23.2 \pm 2.2$ \\
\hline SAV-B & $\begin{array}{c}-23.0^{72} \\
-24.5^{36} \\
-24.9 \pm 0.4^{80} \\
-26.7^{19} \\
-24.8 \pm 2.0\end{array}$ & $6.0 \pm 0.2$ & $\begin{array}{c}32.0 \\
30.4 \pm 0.2^{36,80} \\
25.8 \pm 1.2^{81} \\
29.4 \pm 2.6\end{array}$ & $18.4 \pm 4.0$ \\
\hline Complex & $\begin{array}{c}\Delta \mathrm{S}^{\circ} \mathbf{r x n} \\
\left(\mathrm{cal} / \mathrm{mol}^{\circ} \mathrm{K}\right)\end{array}$ & $\begin{array}{c}\Delta \mathbf{S}^{\circ} \neq, \text { forward } \\
\left(\text { cal } / \mathrm{mol}^{\circ} \mathbf{K}\right)\end{array}$ & $\begin{array}{c}\Delta \mathrm{S}^{\circ \neq}{ }^{\ddagger} \text { backwards } \\
\left(\text { cal } / \mathrm{mol}^{\circ} \mathrm{K}\right)\end{array}$ & $\begin{array}{c}\Delta \mathrm{S}^{\circ \neq} \text { forward }-\Delta \mathbf{S}_{\text {backwards }}^{\circ} \\
\left(\mathrm{cal} / \mathrm{mol}^{\circ} \mathrm{K}\right)\end{array}$ \\
\hline$A V-B$ & $-8.9^{79}$ & $32.0 \pm 1.2$ & $43.0 \pm 2.0^{18 d}$ & $-11.0 \pm 2.5$ \\
\hline SAV-B & $-21.0^{36}$ & $6.7 \pm 1.6$ & $\begin{array}{c}29.9 \pm 2.0^{18 d} \\
25.8^{82} \\
18.8 \pm 0.3^{36,80,81} \\
24.8 \pm 4.5\end{array}$ & $18.1 \pm 4.5$ \\
\hline Complex & $\begin{array}{c}\mathrm{G}^{\circ} \mathrm{rxn} \\
(\mathrm{kcal} / \mathrm{mol})\end{array}$ & $\begin{array}{c}G^{\circ} \neq, \text { forward } \\
\text { (kcal/mol) }\end{array}$ & $\begin{array}{c}\mathrm{G}^{\circ} \neq, \text { backwards } \\
\quad(\mathrm{kcal} / \mathrm{mol})\end{array}$ & $\begin{array}{c}\Delta G^{\circ} \neq, \text { forward }-\Delta G^{\circ}, \text { backwards } \\
\text { (kcal } / \mathrm{mol})\end{array}$ \\
\hline$A V-B$ & $\begin{array}{c}-20.5^{77} \\
-20.8^{79} \\
-20.7 \pm 0.3\end{array}$ & $4.7 \pm 0.3$ & $24.7 \pm 2.0^{18, d}$ & $25.0 \pm 4.0$ \\
\hline SAV-B & $\begin{array}{c}-18.1^{36} \\
-18.3^{83,84} \\
-18.2 \pm 0.2\end{array}$ & $4.0 \pm 0.6$ & $\begin{array}{c}21.4 \pm 2.0^{44} \\
24.8 \pm 0.3^{80, \mathrm{e}} \\
24.6 \pm 0.3^{36,81} \\
23.6 \pm 1.5^{3}\end{array}$ & $19.6 \pm 2.5$ \\
\hline
\end{tabular}


${ }^{a}$ According to the best fitting model with one transition state and non-intermediates. The forward and reverse rate constants were used to calculate, with Arrhenius plots, the respective forward and backward activation energies, $\mathrm{E}_{\mathrm{a}}$ forward and $\mathrm{E}_{\mathrm{a}}$ backwards, respectively. The difference of these activation energies results in $\Delta \mathrm{E}$ (column 4 ) which were equivalent to an averaged $\Delta \mathrm{H}_{\mathrm{Rxn}}^{\mathrm{o}}$ (column 1) of multiple independent calorimetry studies. Similarly, analysis was carried out for reaction Gibbs free energy $\left(\Delta \mathrm{G}_{\mathrm{Rxn}}^{\circ}\right)$ and entropy $\left(\Delta \mathrm{S}_{\mathrm{Rxn}}{ }\right)$.

${ }^{b}$ Column 4 is the subtraction of column 2 minus column 3 and should be equivalent to experimental reaction values obtained from multiple studies thus confirming the accuracy of the proposed model.

${ }^{c}$ Averaged values are shown below the dotted line.

${ }^{d}$ Calculated from the plotted data.

${ }^{e}$ Calculated at $25^{\circ} \mathrm{C}$. 
Table 4. Spectroscopic parameters of the dye-labeled biotin probes and respective complexes with AV and SAV.

\begin{tabular}{|c|c|c|c|c|c|c|c|c|c|}
\hline Sample a & 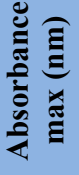 & 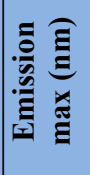 & $\tau^{\mathbf{b}}$ & $\tau^{\circ} \mathbf{c}$ & $\Phi^{d}$ & QY & $1-S^{e}$ & $\mathbf{r}_{\mathrm{ss}} \mathbf{f}$ & $\begin{array}{c}\Omega \mathrm{g} \\
\text { (degrees) }\end{array}$ \\
\hline BFI & 494 & 530 & $4.03 \pm 0.01$ & $5.2 \pm 0.2$ & $0.81 \pm 0.04$ & $0.52 \pm 0.02$ & $0.65 \pm 0.06$ & $0.021 \pm 0.002$ & 90 \\
\hline AV-BFI & 498 & 528 & $4.22 \pm 0.01$ & $4.7 \pm 0.1$ & $0.90 \pm 0.02$ & $0.44 \pm 0.01$ & $0.49 \pm 0.03$ & $0.180 \pm 0.003$ & $51 \pm 2$ \\
\hline $\begin{array}{c}\text { SAV-BFI }{ }^{\mathrm{h}} \\
\text { mono-ionic } \\
\text { SAV-BFI } \\
\text { di-ionic }\end{array}$ & 472 & 515 & $3.0 \pm 0.1$ & $\begin{array}{l}8.1 \pm 0.1 \\
4.5 \pm 0.1\end{array}$ & - & $0.06 \pm 0.01^{\mathrm{i}}$ & $0.18 \pm 0.02$ & $0.171 \pm 0.008$ & $51 \pm 2$ \\
\hline BcO & 495 & 523 & $3.75 \pm 0.04$ & $4.4 \pm 0.1$ & $0.85 \pm 0.02$ & $0.91 \pm 0.02$ & $1.00 \pm 0.02$ & $0.023 \pm 0.002$ & 90 \\
\hline $\mathrm{AV}-\mathrm{BcO}$ & 497 & 524 & $4.35 \pm 0.01$ & $4.9 \pm 0.1$ & $0.88 \pm 0.02$ & $0.62 \pm 0.02$ & $0.70 \pm 0.03$ & $0.187 \pm 0.009$ & $50 \pm 2$ \\
\hline SAV-BcO & 497 & 524 & $3.98 \pm 0.01$ & $4.8 \pm 0.1$ & $0.83 \pm 0.02$ & $0.21 \pm 0.01$ & $0.25 \pm 0.02$ & $0.053 \pm 0.005$ & $50 \pm 2$ \\
\hline $\begin{array}{c}\text { biotin- } \\
\text { DNA }_{d s}{ }^{*} \mathbf{F l}\end{array}$ & 502 & 520 & $3.12 \pm 0.08$ & $4.3 \pm 0.1$ & $0.75 \pm 0.04$ & $0.22 \pm 0.01$ & $0.29 \pm 0.02$ & $0.077 \pm 0.005$ & $49 \pm 2$ \\
\hline $\begin{array}{l}\text { AV-biotin- } \\
\text { DNA }_{\text {ds }}{ }^{*} \text { Fl }\end{array}$ & 499 & 521 & $3.80 \pm 0.05$ & $3.9 \pm 0.1$ & $0.98 \pm 0.02$ & $0.36 \pm 0.01$ & $0.37 \pm 0.02$ & $0.150 \pm 0.007$ & $40 \pm 3$ \\
\hline $\begin{array}{c}\text { SAV- } \\
\text { biotin- } \\
\text { DNA }_{d s}{ }^{*} \text { Fl }\end{array}$ & 499 & 521 & $3.86 \pm 0.01$ & $3.9 \pm 0.1$ & $1.00 \pm 0.02$ & $0.18 \pm 0.01$ & $0.18 \pm 0.02$ & $0.082 \pm 0.001$ & $51 \pm 3$ \\
\hline
\end{tabular}

$a$ Protein excess $\left(\mathrm{AB}_{1}\right.$ filling model). The chemical environment is altered after complex formation as changes in the following properties shown: shifting in absorbance peaks (abs max, supporting Information, Figure S1) and fluorescence emission peaks (emi max, Supporting Information, Figure S3), lifetimes $(\tau)$, dynamic quenching $(\Phi)$, static quantum yields $(Q Y)$, fluorescence emitting population (1-S) and the cone angle that indicates dye mobility $(\Omega)$.

$b$ Bi-exponential decays were observed for the biotin-DNA $\mathrm{ds}^{*} \mathrm{Fl}$ and $\mathrm{SAV}-\mathrm{BF} 1$ complexes (Supporting Information, Table S3).

${ }^{c} \tau^{\circ}$, is the intrinsic lifetime of the fluorescent dye when there are no other radiationless transitions.

${ }^{d} \Phi=\Sigma \alpha \tau / \tau^{\circ}$, is the dynamic quantum yield. 
$e^{e} 1-\mathrm{S}=\mathrm{QY} / \Phi$, is the fraction of non-statically quenched molecules.

${ }^{f} \mathrm{r}_{\mathrm{ss}}$, is the steady state anisotropy measured at $20^{\circ} \mathrm{C}$.

$g \Omega$, is the cone angle.

${ }^{h}$ The absorbance spectrum of the SAV-BFl complex (Supporting Information, Figure S1) and the detection of the corresponding lifetimes of 3.0 and $4.1 \mathrm{~ns}^{85,86}$ indicates the presence of both $\mathrm{Fl}^{1-}$ and $\mathrm{Fl}^{2-}$, respectively. ${ }^{72} \mathrm{We}$ used these reported lifetimes to calculate the pre-exponentials values $(\alpha)$ of each fluorescent species in the SAV-BFl complex. The intrinsic lifetime of $F 1^{1-}$ was calculated by dividing the lifetime $(3.0 \mathrm{~ns})$ over the absolute quantum yield $(0.37) .{ }^{43} \mathrm{We}$ calculated the $(1-\mathrm{S})_{\mathrm{Fl}}{ }^{1-}$ by assuming that $(1-\mathrm{S})_{\mathrm{Fl}}{ }^{2-}$ is that of $\mathrm{AV}-\mathrm{BFl}$ (with contains only $\mathrm{Fl}^{2-}$ ) and solving the following equation: $\frac{\alpha_{F l^{2-}}}{\alpha_{F l^{1-}}}=\frac{[C \varepsilon(1-S) D]_{F l^{2-}}}{[C \varepsilon(1-S) D]_{F l^{1-}}}$, where $\mathrm{C}$ is the concentration, $\varepsilon$ is the molar absorptivity at $470 \mathrm{~nm}, \mathrm{D}$ is the fraction of photons under a band width of $520 \mathrm{~nm} \pm 5 \mathrm{~nm}$ of the normalized emission spectrum of $\mathrm{Fl}^{2-}$ and $\mathrm{Fl}^{1-}$ (taken from fig ${ }^{86}$ ) which values were 0.229 and 0.158 , respectively. The $\alpha_{\mathrm{Fl}}{ }^{2-}$ and $\alpha_{\mathrm{Fl}}{ }^{1-}$ were 0.611 and 0.388 , respectively; for a ratio of 1.574 . The concentration of $\mathrm{Fl}^{2-}$ and $\mathrm{Fl}^{1-}$ were acquired by solving simultaneously the following equations: abs ${ }^{494}=\left(\varepsilon^{494 *} \mathrm{C}\right)_{\mathrm{Fl}}{ }^{1-}+\left(\varepsilon^{494}{ }^{*} \mathrm{C}\right)_{\mathrm{Fl}}{ }^{2-}$ and $\mathrm{abs}^{472}=\varepsilon^{472} \mathrm{C}_{\mathrm{Fl}}{ }^{1-}+\varepsilon^{472} \mathrm{C}_{\mathrm{Fl}}{ }^{2-}$, where $a b s$ is the absorbance at $494 \mathrm{~nm}$ and $472 \mathrm{~nm}$ of the SAV-BFl absorbance spectrum; and the $\varepsilon$ of $\mathrm{Fl}^{1-}$ is $25 \mathrm{mM}^{-1} \mathrm{~cm}^{-1}$ and $29 \mathrm{mM}^{-1} \mathrm{~cm}^{-1}$ at $494 \mathrm{~nm}$ and $472 \mathrm{~nm}$, respectively; and $\varepsilon$ of $\mathrm{Fl}^{2-}$ were $76 \mathrm{mM}^{-1} \mathrm{~cm}^{-1}$ and $35 \mathrm{mM}^{-}$ ${ }^{1} \mathrm{~cm}^{-1} 86,87$ at $494 \mathrm{~nm}$ and $472 \mathrm{~nm}$. Thus, for the SAV-BFl complex, the concentration ratio of $\mathrm{Fl}^{1-}$ $/ \mathrm{Fl}^{2-}$ was 3.5

${ }^{i}$ The QY and $\Phi$ of the SAV-BFl complex could not be resolved for each of the two Fl species. 
Table 1. Comparison of the association rate constants $\left(\mathrm{k}_{\mathrm{on}}\right)$ obtained by fluorescence change, $\overline{\boldsymbol{F}}(\boldsymbol{t})$, and corrected fluorescence anisotropy, $\overline{\boldsymbol{r} \boldsymbol{F}}(\boldsymbol{t})$, of $\mathrm{BcO}(20 \mathrm{nM})$ binding to $\mathrm{AV}$ at several temperatures, protein concentrations and $\mathrm{pH} 8 .^{\mathrm{a}}$

\begin{tabular}{|c|c|c|c|c|c|c|c|c|c|c|c|}
\hline \multirow{3}{*}{\begin{tabular}{c|} 
Complex $^{\mathrm{a}}$ \\
$\mathrm{k}_{\mathrm{on}}, \mathrm{AV}-\mathrm{BcO}$ \\
Temp.
\end{tabular}} & $\begin{array}{c}25^{\circ} \mathrm{C} \\
\left(\times 10^{-6} \mathrm{M}^{-1} \mathrm{~s}^{-1}\right)\end{array}$ & $\begin{array}{c}20^{\circ} \mathrm{C} \\
\left(\times 10^{-6} \mathrm{M}^{-1} \mathrm{~s}^{-1}\right)\end{array}$ & \multicolumn{2}{|c|}{$\begin{array}{c}15^{\circ} \mathrm{C} \\
\left(\times 10^{-6} \mathrm{M}^{-1} \mathrm{~s}^{-1}\right)\end{array}$} & \multicolumn{2}{|c|}{$\begin{array}{c}10^{\circ} \mathrm{C} \\
\left(\times 10^{-6} \mathrm{M}^{-1} \mathrm{~s}^{-1}\right)\end{array}$} & \multicolumn{2}{|c|}{$\begin{array}{l}\mathrm{E}_{\mathrm{a}} \text { Forward } \\
(\mathrm{kcal} / \mathrm{mol})\end{array}$} & \multicolumn{2}{|c|}{$\begin{array}{c}\Delta \mathbf{S}^{\dagger} \\
\left(\mathbf{c a l} /{ }^{\circ} \mathbf{K} \cdot \mathbf{m o l}\right)\end{array}$} & \multirow[t]{2}{*}{$\begin{array}{r}\Delta G^{\ddagger} \\
(\mathrm{kcal} / \mathrm{m}\end{array}$} \\
\hline & \multicolumn{5}{|c|}{$\bar{F}(t), \times 10^{-6} \mathrm{M}^{-1} \mathrm{~s}^{-1}$} & \multicolumn{5}{|c|}{$\overline{r F}(t), \times 10^{-6} M^{-1} s^{-1}$} & \\
\hline & $260 \mathrm{nM}$ & \multicolumn{2}{|c|}{$520 \mathrm{nM}$} & \multicolumn{2}{|c|}{$1040 \mathrm{nM}$} & \multicolumn{2}{|c|}{$260 \mathrm{nM}$} & \multicolumn{2}{|c|}{$520 \mathrm{nM}$} & \multicolumn{2}{|c|}{$1040 \mathrm{nM}$} \\
\hline $25^{\circ} \mathrm{C}$ & $9.5 \pm 0.1$ & \multicolumn{2}{|c|}{$9.5 \pm 0.3$} & \multicolumn{2}{|c|}{$9.7 \pm 0.3$} & \multicolumn{2}{|c|}{$9.5 \pm 0.1$} & \multicolumn{2}{|c|}{$9.5 \pm 0.1$} & \multicolumn{2}{|c|}{$9.4 \pm 0.2$} \\
\hline $20{ }^{\circ} \mathrm{C}$ & $5.7 \pm 0.1$ & \multicolumn{2}{|c|}{$5.9 \pm 0.3$} & \multicolumn{2}{|c|}{$6.0 \pm 0.1$} & \multicolumn{2}{|c|}{$5.9 \pm 0.1$} & \multicolumn{2}{|c|}{$5.8 \pm 0.1$} & \multicolumn{2}{|c|}{$6.1 \pm 0.1$} \\
\hline $15^{\circ} \mathrm{C}$ & $4.1 \pm 0.1$ & \multicolumn{2}{|c|}{$3.95 \pm 0.1$} & \multicolumn{2}{|c|}{$3.9 \pm 0.2$} & \multicolumn{2}{|c|}{$4.0 \pm 0.1$} & \multicolumn{2}{|c|}{$3.82 \pm 0.1$} & \multicolumn{2}{|c|}{$4.0 \pm 0.2$} \\
\hline $10{ }^{\circ} \mathrm{C}$ & $2.4 \pm 0.1$ & \multicolumn{2}{|c|}{$2.6 \pm 0.2$} & \multicolumn{2}{|c|}{$2.5 \pm 0.2$} & \multicolumn{2}{|c|}{$2.7 \pm 0.1$} & \multicolumn{2}{|c|}{$2.7 \pm 0.1$} & \multicolumn{2}{|c|}{$2.7 \pm 0.1$} \\
\hline
\end{tabular}

aThe $\overline{\boldsymbol{F}}(\boldsymbol{t})$ and $\overline{\boldsymbol{r} F}(\boldsymbol{t})$ signals were equivalent as they tracked in the errors the association process of dye-labeled $\mathrm{B}_{7}$ binding to the proteins under pseudo first order conditions. 


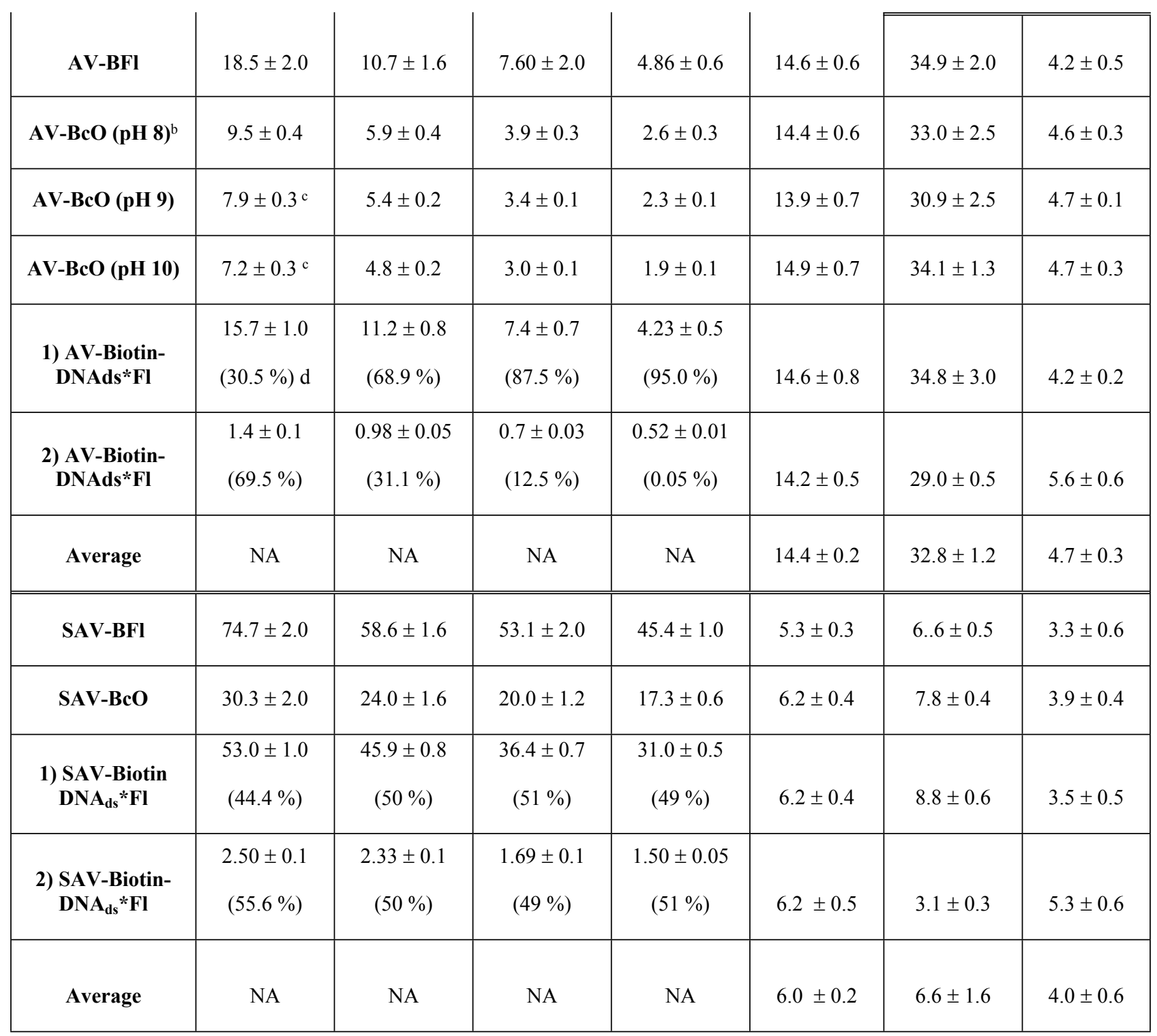

Table 2. Association rate constants $\left(\mathrm{k}_{\mathrm{on}}\right)$ and thermodynamic values of the dye-labeled biotin binding to AV and SAV.

aThe probes were $\mathrm{BFl}, \mathrm{BcO}$, and biotin attached to a nucleotide in a 14-mer DNA duplex. The thermodynamic values were acquired from global fitting of the rate constants ${ }^{39,42}$ for the most probable model which resulted in simple reaction with a transition state without intermediates. In case of biotin-DNA duplex, the reaction model was a two-serial reaction model also with one transition state without intermediates. The nature of the serial reaction is probably caused by two $\mathrm{B}_{7}$ populations with different spatial orientation.

${ }^{b}$ The $\mathrm{k}_{\mathrm{on}}$ were averaged from data in Table 1

${ }^{c}$ Calculated from an Arrhenius plot. 
bioRxiv preprint doi: https://doi.org/10.1101/410548; this version posted September 6,2018 . The copyright holder for this preprint (which was not certified by peer review) is the author/funder, who has granted bioRxiv a license to display the preprint in perpetuity. It is made available under aCC-BY 4.0 International license.

${ }^{d}$ The pre-exponentials (in parenthesis) of $\mathrm{k}_{\mathrm{on} 1}$ and $\mathrm{k}_{\mathrm{on} 2}$ were renormalized after removing a third process associated to remaining photobleaching. 
Table 3. Thermodynamic cycles of biotin binding to AV and SAV for one transition state. ${ }^{\mathrm{a}}$

\begin{tabular}{|c|c|c|c|c|}
\hline Complex & $\begin{array}{c}\Delta H^{\circ} \mathbf{r x n} \\
(\mathrm{kcal} / \mathrm{mol})\end{array}$ & $\begin{array}{l}\text { Ea forwards } \\
(\mathrm{kcal} / \mathrm{mol})\end{array}$ & $\begin{array}{l}\text { Ea backwards } \\
(\mathrm{kcal} / \mathrm{mol})\end{array}$ & $\begin{array}{c}\Delta \mathbf{E}=\mathbf{E a}_{\text {forward }}-\mathbf{E a}_{\text {backwards }} \\
{(\mathrm{kcal} / \mathrm{mol})^{b}}^{b}\end{array}$ \\
\hline$A V-B$ & $\begin{array}{l}-20.3 \pm 0.3^{77} \\
-22.5 \pm 0.1^{78} \\
-26.7^{36} \\
-23.4 \pm 0.3^{79} \\
-23.2 \pm 1.7^{c}\end{array}$ & $14.4 \pm 0.2$ & $37.6 \pm 2.0^{18}$ & $23.2 \pm 2.2$ \\
\hline SAV-B & $\begin{array}{c}-23.0^{72} \\
-24.5^{36} \\
-24.9 \pm 0.4^{80} \\
-26.7^{19} \\
-24.8 \pm 2.0\end{array}$ & $6.0 \pm 0.2$ & $\begin{array}{c}32.0 \\
30.4 \pm 0.2^{36,80} \\
25.8 \pm 1.2^{81} \\
29.4 \pm 2.6\end{array}$ & $18.4 \pm 4.0$ \\
\hline Complex & $\begin{array}{c}\Delta \mathrm{S}^{\circ} \mathbf{r x n} \\
\left(\mathrm{cal} / \mathrm{mol}^{\circ} \mathrm{K}\right)\end{array}$ & $\begin{array}{c}\Delta \mathbf{S}^{\circ} \neq, \text { forward } \\
\left(\text { cal } / \mathrm{mol}^{\circ} \mathbf{K}\right)\end{array}$ & $\begin{array}{c}\Delta \mathrm{S}^{\circ \neq}{ }^{\ddagger} \text { backwards } \\
\left(\text { cal } / \mathrm{mol}^{\circ} \mathrm{K}\right)\end{array}$ & $\begin{array}{c}\Delta \mathrm{S}^{\circ \neq} \text { forward }-\Delta \mathbf{S}_{\text {backwards }}^{\circ} \\
\left(\mathrm{cal} / \mathrm{mol}^{\circ} \mathrm{K}\right)\end{array}$ \\
\hline$A V-B$ & $-8.9^{79}$ & $32.0 \pm 1.2$ & $43.0 \pm 2.0^{18 d}$ & $-11.0 \pm 2.5$ \\
\hline SAV-B & $-21.0^{36}$ & $6.7 \pm 1.6$ & $\begin{array}{c}29.9 \pm 2.0^{18 d} \\
25.8^{82} \\
18.8 \pm 0.3^{36,80,81} \\
24.8 \pm 4.5\end{array}$ & $18.1 \pm 4.5$ \\
\hline Complex & $\begin{array}{c}\mathrm{G}^{\circ} \mathrm{rxn} \\
(\mathrm{kcal} / \mathrm{mol})\end{array}$ & $\begin{array}{c}G^{\circ} \neq, \text { forward } \\
\text { (kcal/mol) }\end{array}$ & $\begin{array}{c}\mathrm{G}^{\circ} \neq, \text { backwards } \\
\quad(\mathrm{kcal} / \mathrm{mol})\end{array}$ & $\begin{array}{c}\Delta G^{\circ} \neq, \text { forward }-\Delta G^{\circ}, \text { backwards } \\
\text { (kcal } / \mathrm{mol})\end{array}$ \\
\hline$A V-B$ & $\begin{array}{c}-20.5^{77} \\
-20.8^{79} \\
-20.7 \pm 0.3\end{array}$ & $4.7 \pm 0.3$ & $24.7 \pm 2.0^{18, d}$ & $25.0 \pm 4.0$ \\
\hline SAV-B & $\begin{array}{c}-18.1^{36} \\
-18.3^{83,84} \\
-18.2 \pm 0.2\end{array}$ & $4.0 \pm 0.6$ & $\begin{array}{c}21.4 \pm 2.0^{44} \\
24.8 \pm 0.3^{80, \mathrm{e}} \\
24.6 \pm 0.3^{36,81} \\
23.6 \pm 1.5^{3}\end{array}$ & $19.6 \pm 2.5$ \\
\hline
\end{tabular}


${ }^{a}$ According to the best fitting model with one transition state and non-intermediates. The forward and reverse rate constants were used to calculate, with Arrhenius plots, the respective forward and backward activation energies, $\mathrm{E}_{\mathrm{a}}$ forward and $\mathrm{E}_{\mathrm{a}}$ backwards, respectively. The difference of these activation energies results in $\Delta \mathrm{E}$ (column 4 ) which were equivalent to an averaged $\Delta \mathrm{H}_{\mathrm{Rxn}}^{\mathrm{o}}$ (column 1) of multiple independent calorimetry studies. Similarly, analysis was carried out for reaction Gibbs free energy $\left(\Delta \mathrm{G}_{\mathrm{Rxn}}^{\circ}\right)$ and entropy $\left(\Delta \mathrm{S}_{\mathrm{Rxn}}{ }\right)$.

${ }^{b}$ Column 4 is the subtraction of column 2 minus column 3 and should be equivalent to experimental reaction values obtained from multiple studies thus confirming the accuracy of the proposed model.

${ }^{c}$ Averaged values are shown below the dotted line.

${ }^{d}$ Calculated from the plotted data.

${ }^{e}$ Calculated at $25{ }^{\circ} \mathrm{C}$. 
Table 4. Spectroscopic parameters of the dye-labeled biotin probes and respective complexes with AV and SAV.

\begin{tabular}{|c|c|c|c|c|c|c|c|c|c|}
\hline Sample a & 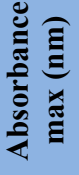 & 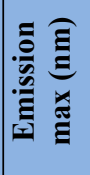 & $\tau^{\mathbf{b}}$ & $\tau^{\circ} \mathbf{c}$ & $\Phi^{d}$ & QY & $1-S^{e}$ & $\mathbf{r}_{\mathrm{ss}} \mathbf{f}$ & $\begin{array}{c}\Omega \mathrm{g} \\
\text { (degrees) }\end{array}$ \\
\hline BFI & 494 & 530 & $4.03 \pm 0.01$ & $5.2 \pm 0.2$ & $0.81 \pm 0.04$ & $0.52 \pm 0.02$ & $0.65 \pm 0.06$ & $0.021 \pm 0.002$ & 90 \\
\hline AV-BFI & 498 & 528 & $4.22 \pm 0.01$ & $4.7 \pm 0.1$ & $0.90 \pm 0.02$ & $0.44 \pm 0.01$ & $0.49 \pm 0.03$ & $0.180 \pm 0.003$ & $51 \pm 2$ \\
\hline $\begin{array}{c}\text { SAV-BFI }{ }^{\mathrm{h}} \\
\text { mono-ionic } \\
\text { SAV-BFI } \\
\text { di-ionic }\end{array}$ & 472 & 515 & $3.0 \pm 0.1$ & $\begin{array}{l}8.1 \pm 0.1 \\
4.5 \pm 0.1\end{array}$ & - & $0.06 \pm 0.01^{\mathrm{i}}$ & $0.18 \pm 0.02$ & $0.171 \pm 0.008$ & $51 \pm 2$ \\
\hline BcO & 495 & 523 & $3.75 \pm 0.04$ & $4.4 \pm 0.1$ & $0.85 \pm 0.02$ & $0.91 \pm 0.02$ & $1.00 \pm 0.02$ & $0.023 \pm 0.002$ & 90 \\
\hline $\mathrm{AV}-\mathrm{BcO}$ & 497 & 524 & $4.35 \pm 0.01$ & $4.9 \pm 0.1$ & $0.88 \pm 0.02$ & $0.62 \pm 0.02$ & $0.70 \pm 0.03$ & $0.187 \pm 0.009$ & $50 \pm 2$ \\
\hline SAV-BcO & 497 & 524 & $3.98 \pm 0.01$ & $4.8 \pm 0.1$ & $0.83 \pm 0.02$ & $0.21 \pm 0.01$ & $0.25 \pm 0.02$ & $0.053 \pm 0.005$ & $50 \pm 2$ \\
\hline $\begin{array}{c}\text { biotin- } \\
\text { DNA }_{d s}{ }^{*} \mathbf{F l}\end{array}$ & 502 & 520 & $3.12 \pm 0.08$ & $4.3 \pm 0.1$ & $0.75 \pm 0.04$ & $0.22 \pm 0.01$ & $0.29 \pm 0.02$ & $0.077 \pm 0.005$ & $49 \pm 2$ \\
\hline $\begin{array}{l}\text { AV-biotin- } \\
\text { DNA }_{\text {ds }}{ }^{*} \text { Fl }\end{array}$ & 499 & 521 & $3.80 \pm 0.05$ & $3.9 \pm 0.1$ & $0.98 \pm 0.02$ & $0.36 \pm 0.01$ & $0.37 \pm 0.02$ & $0.150 \pm 0.007$ & $40 \pm 3$ \\
\hline $\begin{array}{c}\text { SAV- } \\
\text { biotin- } \\
\text { DNA }_{d s}{ }^{*} \text { Fl }\end{array}$ & 499 & 521 & $3.86 \pm 0.01$ & $3.9 \pm 0.1$ & $1.00 \pm 0.02$ & $0.18 \pm 0.01$ & $0.18 \pm 0.02$ & $0.082 \pm 0.001$ & $51 \pm 3$ \\
\hline
\end{tabular}

$a$ Protein excess $\left(\mathrm{AB}_{1}\right.$ filling model). The chemical environment is altered after complex formation as changes in the following properties shown: shifting in absorbance peaks (abs max, supporting Information, Figure S1) and fluorescence emission peaks (emi max, Supporting Information, Figure S3), lifetimes $(\tau)$, dynamic quenching $(\Phi)$, static quantum yields $(Q Y)$, fluorescence emitting population (1-S) and the cone angle that indicates dye mobility $(\Omega)$.

$b$ Bi-exponential decays were observed for the biotin-DNA $\mathrm{ds}^{*} \mathrm{Fl}$ and $\mathrm{SAV}-\mathrm{BF} 1$ complexes (Supporting Information, Table S3).

${ }^{c} \tau^{\circ}$, is the intrinsic lifetime of the fluorescent dye when there are no other radiationless transitions.

${ }^{d} \Phi=\Sigma \alpha \tau / \tau^{\circ}$, is the dynamic quantum yield. 
$e^{e} 1-\mathrm{S}=\mathrm{QY} / \Phi$, is the fraction of non-statically quenched molecules.

${ }^{f} \mathrm{r}_{\mathrm{ss}}$, is the steady state anisotropy measured at $20^{\circ} \mathrm{C}$.

$g \Omega$, is the cone angle.

${ }^{h}$ The absorbance spectrum of the SAV-BFl complex (Supporting Information, Figure S1) and the detection of the corresponding lifetimes of 3.0 and $4.1 \mathrm{~ns}^{85,86}$ indicates the presence of both $\mathrm{Fl}^{1-}$ and $\mathrm{Fl}^{2-}$, respectively. ${ }^{72} \mathrm{We}$ used these reported lifetimes to calculate the pre-exponentials values $(\alpha)$ of each fluorescent species in the SAV-BFl complex. The intrinsic lifetime of $F 1^{1-}$ was calculated by dividing the lifetime $(3.0 \mathrm{~ns})$ over the absolute quantum yield $(0.37) .{ }^{43} \mathrm{We}$ calculated the $(1-\mathrm{S})_{\mathrm{Fl}}{ }^{1-}$ by assuming that $(1-\mathrm{S})_{\mathrm{Fl}}{ }^{2-}$ is that of $\mathrm{AV}-\mathrm{BFl}$ (with contains only $\mathrm{Fl}^{2-}$ ) and solving the following equation: $\frac{\alpha_{F l^{2-}}}{\alpha_{F l^{1-}}}=\frac{[C \varepsilon(1-S) D]_{F L^{2-}}}{[C \varepsilon(1-S) D]_{F l^{1-}}}$, where $\mathrm{C}$ is the concentration, $\varepsilon$ is the molar absorptivity at $470 \mathrm{~nm}, \mathrm{D}$ is the fraction of photons under a band width of $520 \mathrm{~nm} \pm 5 \mathrm{~nm}$ of the normalized emission spectrum of $\mathrm{Fl}^{2-}$ and $\mathrm{Fl}^{1-}$ (taken from fig ${ }^{86}$ ) which values were 0.229 and 0.158 , respectively. The $\alpha_{\mathrm{Fl}}{ }^{2-}$ and $\alpha_{\mathrm{Fl}}{ }^{1-}$ were 0.611 and 0.388 , respectively; for a ratio of 1.574 . The concentration of $\mathrm{Fl}^{2-}$ and $\mathrm{Fl}^{1-}$ were acquired by solving simultaneously the following equations: abs ${ }^{494}=\left(\varepsilon^{494 *} \mathrm{C}\right)_{\mathrm{Fl}}{ }^{1-}+\left(\varepsilon^{494}{ }^{*} \mathrm{C}\right)_{\mathrm{Fl}}{ }^{2-}$ and $\mathrm{abs}^{472}=\varepsilon^{472} \mathrm{C}_{\mathrm{Fl}}{ }^{1-}+\varepsilon^{472} \mathrm{C}_{\mathrm{Fl}}{ }^{2-}$, where $a b s$ is the absorbance at $494 \mathrm{~nm}$ and $472 \mathrm{~nm}$ of the SAV-BFl absorbance spectrum; and the $\varepsilon$ of $\mathrm{Fl}^{1-}$ is $25 \mathrm{mM}^{-1} \mathrm{~cm}^{-1}$ and $29 \mathrm{mM}^{-1} \mathrm{~cm}^{-1}$ at $494 \mathrm{~nm}$ and $472 \mathrm{~nm}$, respectively; and $\varepsilon$ of $\mathrm{Fl}^{2-}$ were $76 \mathrm{mM}^{-1} \mathrm{~cm}^{-1}$ and $35 \mathrm{mM}^{-}$ ${ }^{1} \mathrm{~cm}^{-1} 86,87$ at $494 \mathrm{~nm}$ and $472 \mathrm{~nm}$. Thus, for the SAV-BFl complex, the concentration ratio of $\mathrm{Fl}^{1-}$ $/ \mathrm{Fl}^{2-}$ was 3.5

${ }^{i}$ The QY and $\Phi$ of the SAV-BFl complex could not be resolved for each of the two Fl species. 
Oregon Green 488 ® biocytin, BcO

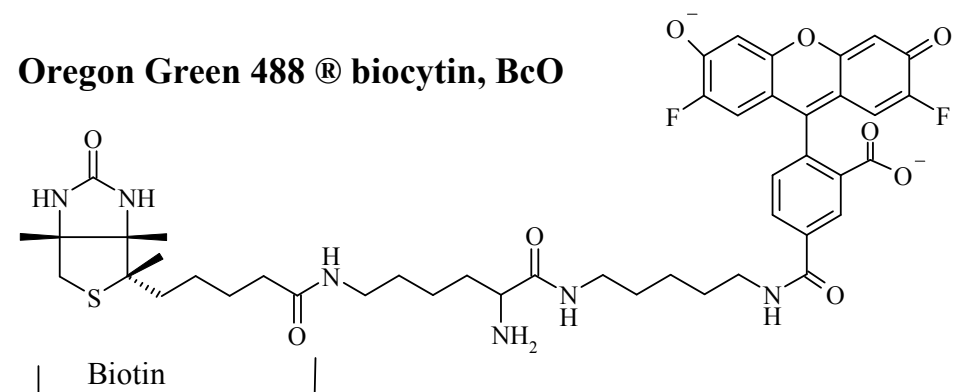

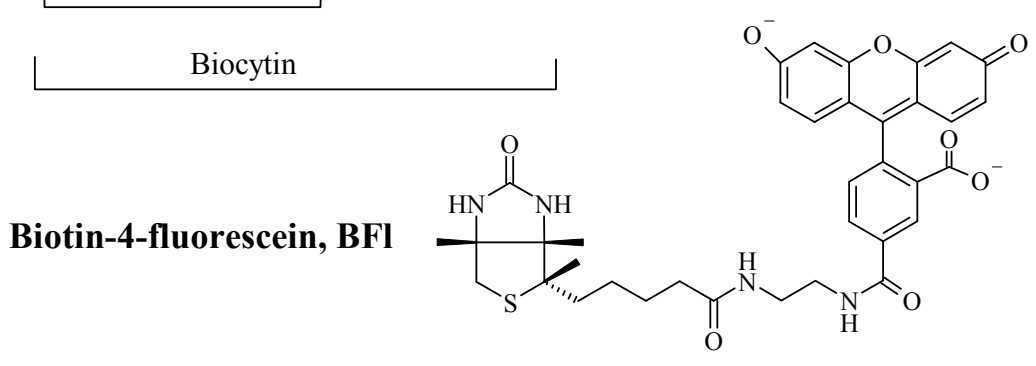

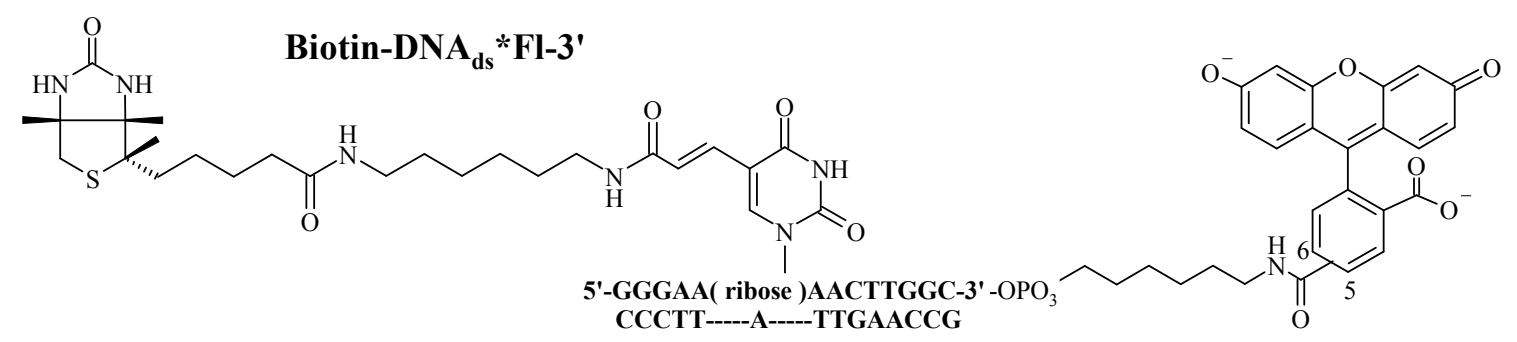

\section{Figure 1}

Figure 1. Dye-labeled $B_{7}$ probes: 1) Biotin-4-fluorescein (BFl) contains a shorter spacer of 10 non-hydrogen atoms between the bicyclic ring and the dye structure. 2) Oregon green 488 ( Biocytin $(\mathrm{BcO})$ has a spacer of 20 non-hydrogen atoms between the bicyclic ring and the fluorescent dye. Biocytin $(\mathrm{Bc})$ is an amide formed with $\mathrm{B}_{7}$ and L-lysine. 3) Biotin-DNA ${ }_{\mathrm{ds}}{ }^{*} \mathrm{Fl}-3$ ', where $\mathrm{B}_{7}$ was attached to a 14-mer DNA duplex labeled with fluorescein (Fl) at the 3' end with 16 non-hydrogen atoms between the bicyclic ring and the thymine cyclic base. Unlabeled $\mathrm{B}_{7}$ was used to find the reaction rate of the final binding site in AV and compare it with the reaction rates of the initial binding site to assessment possible cooperativity. 

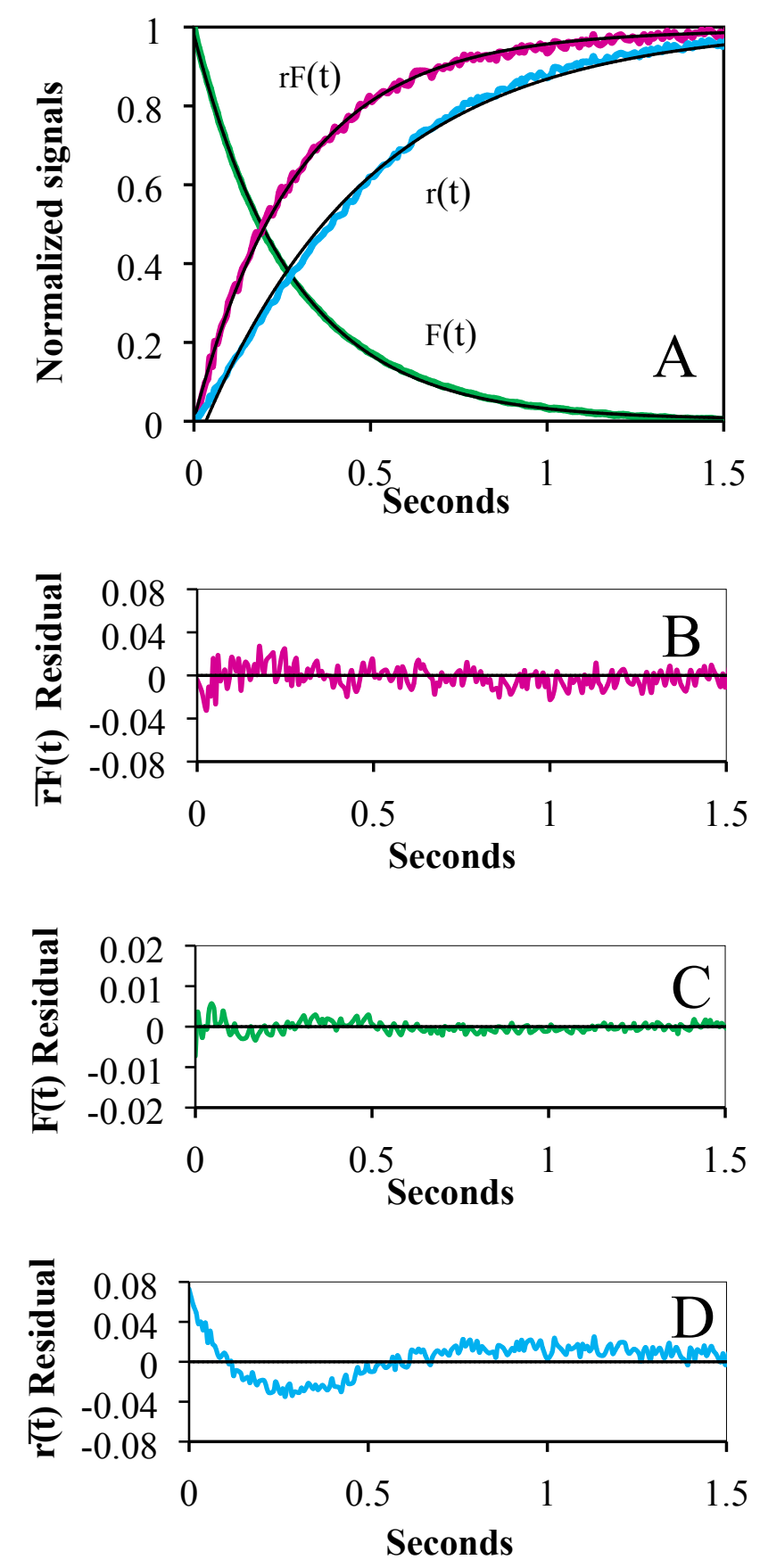

Figure 2 
Figure 2. A Comparison of the fluorescence change, anisotropy and corrected fluorescence anisotropy signals, $\bar{F}(t), \bar{r}(t)$ and $\overline{r F}(t)$, respectively; of $\mathrm{BcO}(20 \mathrm{nM})$ binding to SAV $(200 \mathrm{nM})$ at $10^{\circ} \mathrm{C}$ whose mono-exponential fits (black) resulted in $\mathrm{k}_{\text {on }}$ values of $1.73 \times 10^{7} \mathrm{M}^{-1} \mathrm{~s}^{-1}, 1.72 \times 10^{7}$ $\mathrm{M}^{-1} \mathrm{~s}^{-1}$ and $1.04 \times 10^{7} \mathrm{M}^{-1} \mathrm{~s}^{-1}$ with halftimes of $200.6 \mathrm{~ms}, 201.4 \mathrm{~ms}$ and $332.7 \mathrm{~ms}$, respectively. The $\mathrm{k}_{\text {on }}$ of $\bar{r}(t)$ was $40 \%$ slower than the other two and showed the worse residuals (B-D). The corresponding normalization signals are: $\overline{r F}(t)=[r F(0)-r F(t)] /[r F(0)-r F(\infty)], \bar{F}(t)=\frac{F(t)}{F(0)}$ $=[F(t)-r F(\infty)] /[r F(0)-r F(\infty)]$ and $\bar{r}(t)=[r(0)-r(t)] /[r(0)-r(\infty)]$. 

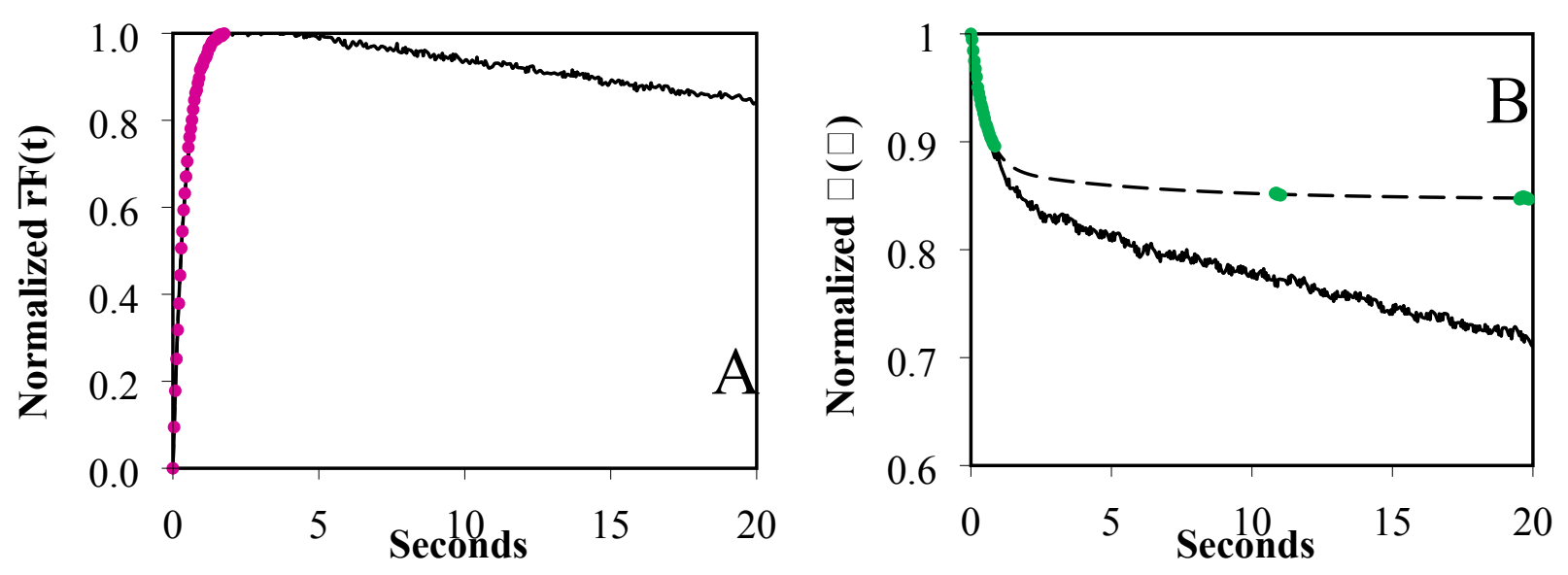

Figure 3

Figure 3. Photobleaching of $\mathrm{BcO}$ binding to $\mathrm{AV}$ at $\left.15{ }^{\circ} \mathrm{C}: \mathbf{A}\right) \overline{r F}(t)$ and $\left.\mathbf{B}\right) \bar{F}(t)$ which corresponding normalization functions are: $\overline{r F}(t)=[r F(0)-r F(t)] /[r F(0)-r F(\infty)]$ and $\bar{F}(t)$ $=\frac{F(t)}{F(0)}=[F(t)-r F(\infty)] /[r F(0)-r F(\infty)]$, respectively. The photobleaching rate constant was elucidated by collecting the reaction with continuous (black) and discontinuous (dashed color) laser illumination, where in the latter case the beam was blocked during the times denoted by dashes and the sample was illuminated only during time intervals around $10 \mathrm{~s}$. The slow photobleaching rate constant varied from $6 \times 10^{-3}$ to $1 \times 10^{-2} \mathrm{~s}^{-1}$, and was laser power dependent. 

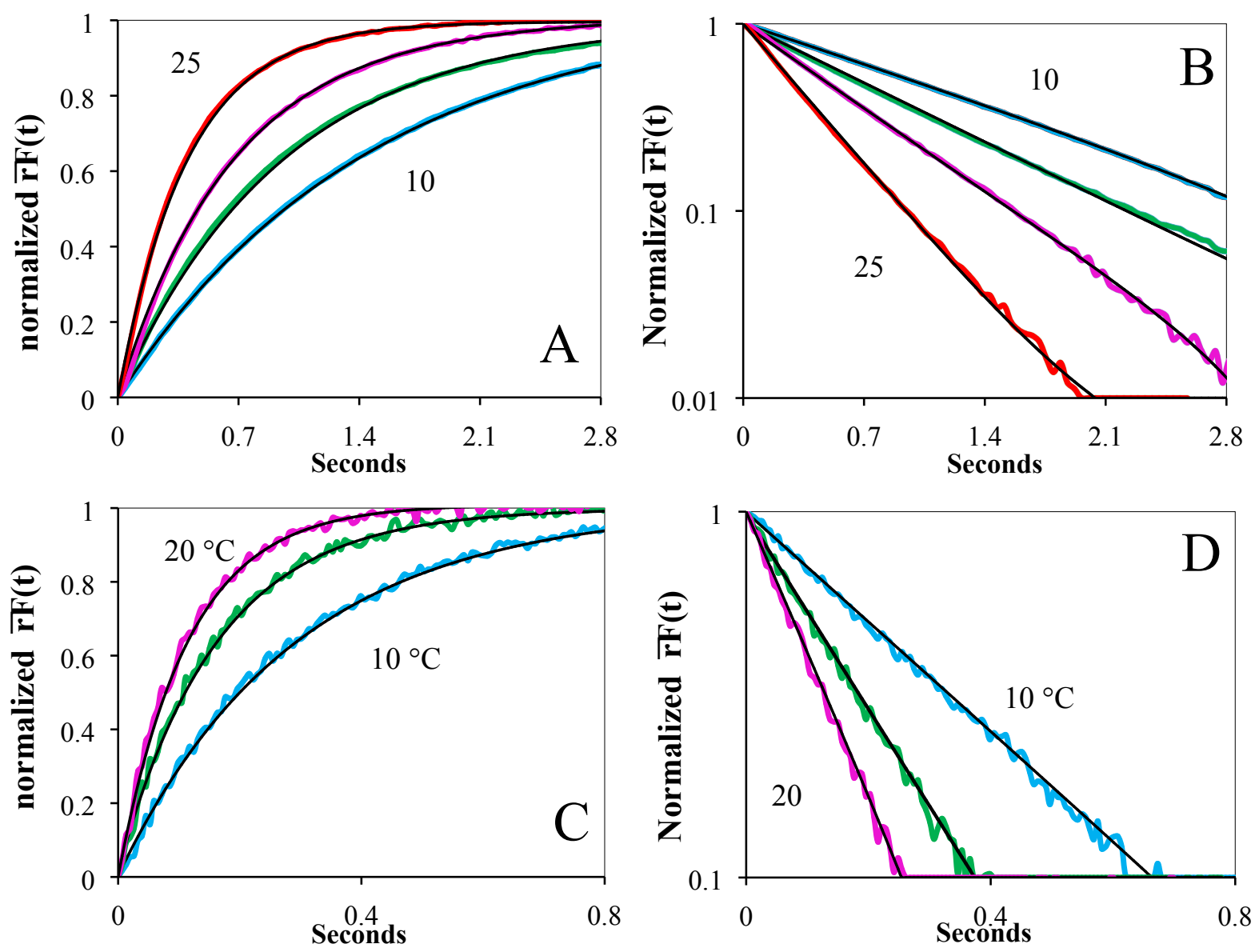

Figure 4

Figure 4. A) Normalized fluorescence anisotropy, $\overline{r F}(t)$, temperature dependence of $\mathrm{BcO}(20 \mathrm{nM})$ binding to $\mathrm{AV}(260 \mathrm{nM})$ at $\mathrm{pH} 8$, normalized as $[r F(0)-r F(t)] /[r F(0)-r F(\infty)]$. The observed (color) and fitted (black line) curves at $25^{\circ} \mathrm{C}$ (top), $20^{\circ} \mathrm{C}$ (upper middle) and $15^{\circ} \mathrm{C}$ (lower middle) and $10^{\circ} \mathrm{C}$ (bottom) had half-times of $280 \mathrm{~ms}, 452 \mathrm{~ms}, 695 \mathrm{~ms}$ and $1024 \mathrm{~ms}$, respectively; and B) shows the corresponding semi-logarithmic plot of $\overline{r F}(t)$. C) Normalized fluorescence anisotropy, $\overline{r F}(t)$, shows a temperature dependence of $\mathrm{BcO}(20 \mathrm{nM})$ binding to $\mathrm{SAV}(200 \mathrm{nM})$ at $\mathrm{pH} 8$, normalized as above (4A). The observed (color) and fitted (black line) curves at $20{ }^{\circ} \mathrm{C}$ (top), 15 ${ }^{\circ} \mathrm{C}$ (middle) and $10{ }^{\circ} \mathrm{C}$ (bottom) had half-times of $79.4 \mathrm{~ms}, 111 \mathrm{~ms}$ and $202 \mathrm{~ms}$, respectively and D) shows the corresponding semi-logarithmic plot of the $\overline{r F}(t)$. 

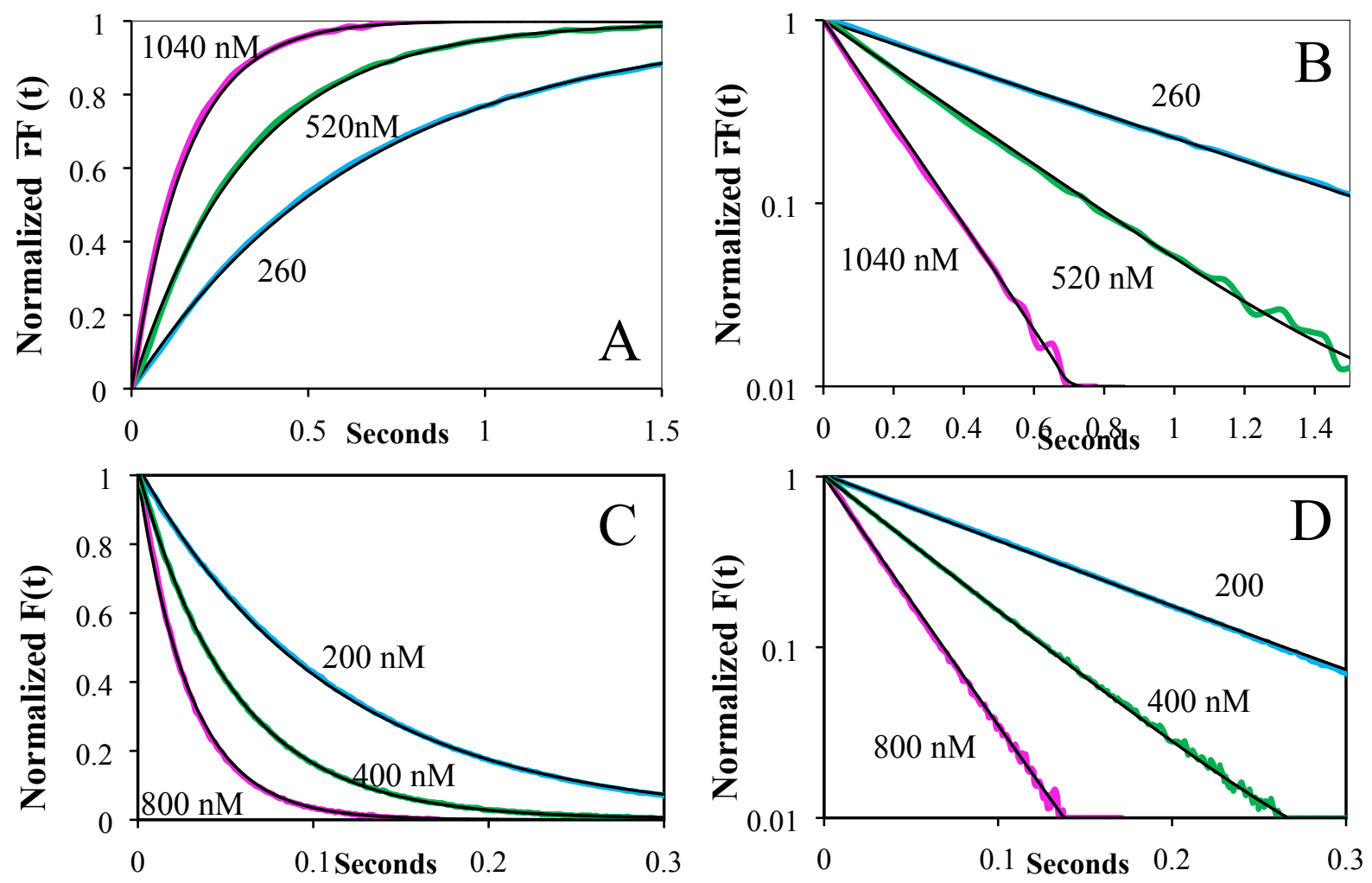

Figure 5

Figure 5. A) Corrected Fluorescence Anisotropy Concentration dependence of $\mathrm{BcO}(20 \mathrm{nM})$ binding to $\mathrm{AV}$ at $\mathrm{pH} 8$ and $20^{\circ} \mathrm{C}$, normalized as $\overline{r F}(t)=[r F(0)-r F(t)] /[r F(0)-r F(\infty)]$. The observed (color) curves were obtained with an AV concentration of $1040 \mathrm{nM}$ (top), $520 \mathrm{nM}$ (middle) and $260 \mathrm{nM}$ (bottom) and the fitted curves (black lines) had halftimes of $109 \mathrm{~ms}, 229 \mathrm{~ms}$ and $455 \mathrm{~ms}$; respectively. B) Shows the corresponding semi-logarithmic plots of $\overline{r F}(t)$. C) Normalized fluorescence change, $\bar{F}(t)$, concentration dependence of BFl (20 nM) binding to SAV at $\mathrm{pH} 8$ and $20{ }^{\circ} \mathrm{C}$. Normalized as followed: $\bar{F}(t)=\frac{F(t)}{F(0)}=[F(t)-r F(\infty)] /[r F(0)-r F(\infty)]$. The observed (color) curves were acquired with SAV concentrations of $200 \mathrm{nM}$ (red), $400 \mathrm{nM}$ (purple) and $800 \mathrm{nM}$ (orange) where the fitted curves (black lines) had halftimes of $77.3 \mathrm{~ms}, 37.7 \mathrm{~ms}$ and $20.6 \mathrm{~ms}$; respectively. D) Shows the corresponding semi-logarithmic plot of $\bar{F}(t)$ 


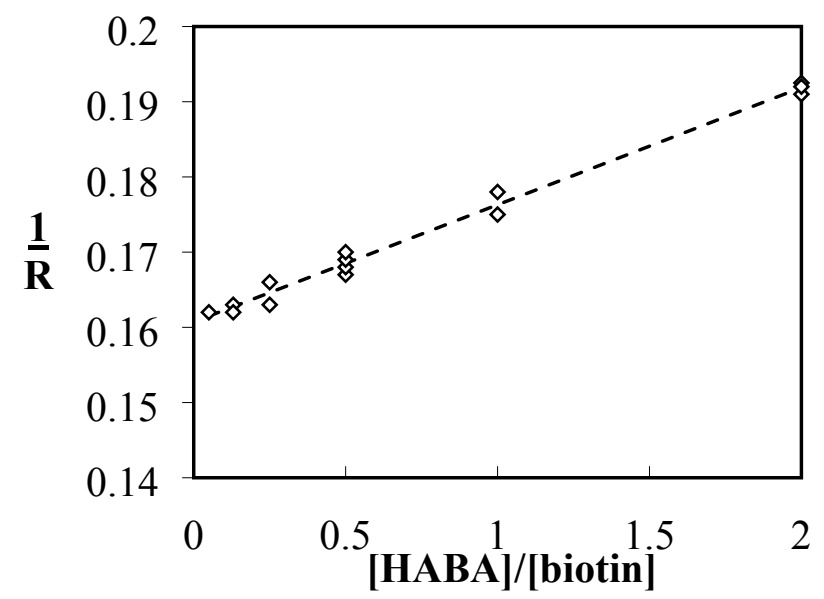

Figure 6

Figure 6. Relaxation kinetics of the AV-HABA complex and unlabeled biotin. The [HABA]/[B] is the concentration ratio of these two ligands and $\mathrm{R}$ is the relaxation rate in $\mathrm{s}^{-1}$ (Eqn. 3). The data points were fitted to a linear regression model yielding a slope and intercept of $0.0156 \pm 0.0012$ and $0.161 \pm 0.005$, respectively, resulting in a $k_{o n}^{B}$ of $5.3 \pm 0.9 \times 10^{6} \mathrm{M}^{-1} \mathrm{~s}^{-1}$ at $23^{\circ} \mathrm{C}$. The additional values required for this calculation were HABA association constant to the $4^{\text {th }}$ site when three HABA molecules are already bound: $k^{A V-H_{1} A B A 3}=5.1 \pm 0.1 \times 10^{5} \mathrm{M}^{-1} \mathrm{~s}^{-1}$ and the HABA dissociation of saturated AV-HABA 4 complex: $k_{-1}^{A V-{ }_{-}^{H A B A 4}}=6.23 \pm 0.11 \mathrm{~s}^{-1}$. The corresponding $\mathrm{K}_{\mathrm{D}} \mathrm{AV}-\mathrm{HABA}=12.2 \pm 0.3 \times 10^{-6} \mathrm{M}$ and is in excellent agreement with the $12 \times 10^{-6} \mathrm{M}$ reported by Green $^{57}$ at $\mathrm{pH} 8$. 

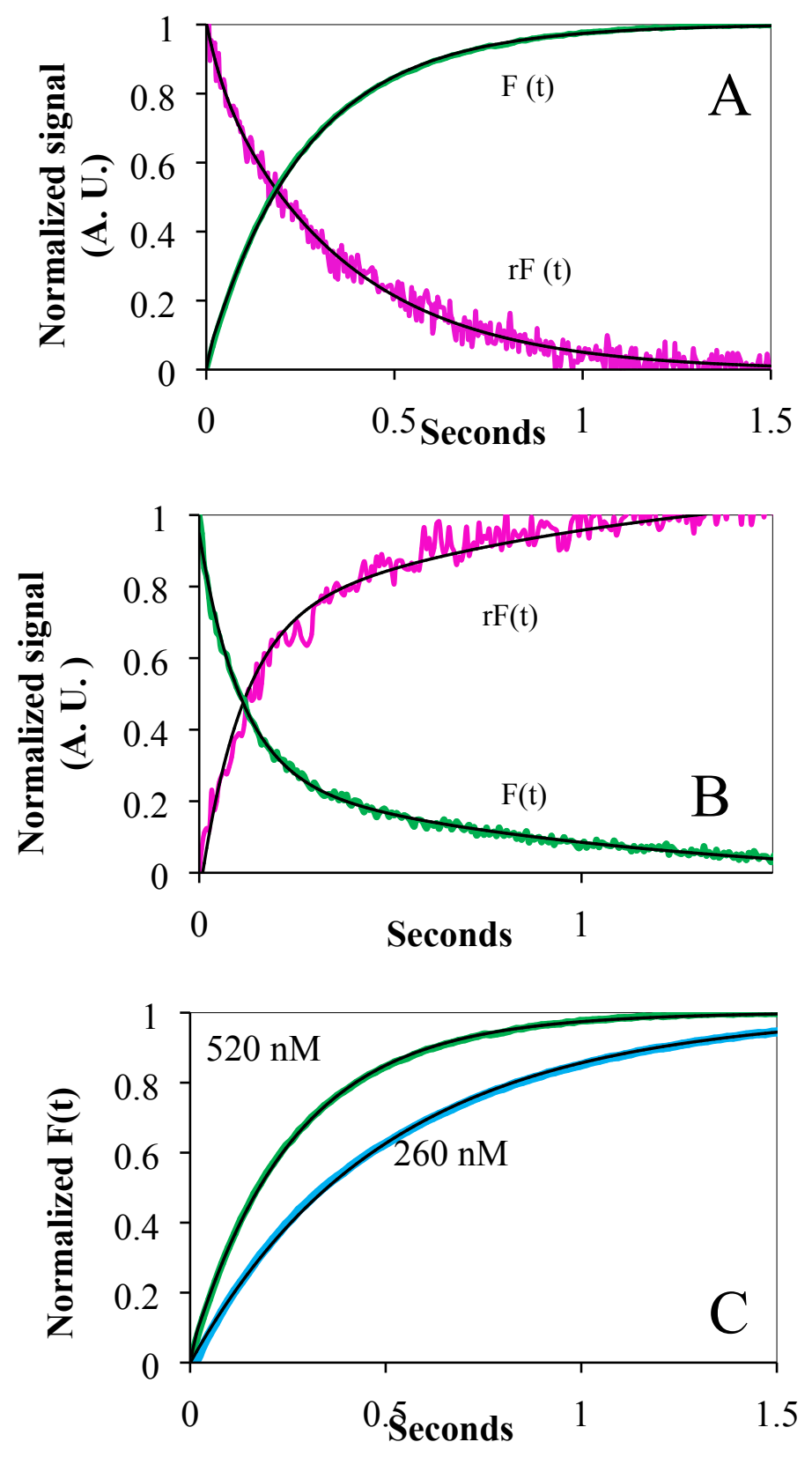

Figure 7

Figure 7. A) Biotin-DNA ${ }_{\mathrm{ds}}{ }^{*} \mathrm{Fl}(20 \mathrm{nM})$ binding to: A) AV (520 nM) and B) SAV (200 nM), at $15^{\circ} \mathrm{C}$. C) Concentration dependence of biotin-DNA ${ }_{\mathrm{ds}} * \mathrm{Fl}(20 \mathrm{nM})$ binding to AV at $15{ }^{\circ} \mathrm{C}$. All curves (black line) were strongly biphasic. Notice the inversion of SF signals. However, the $\bar{F}(t)$ traces were in prefect agreement with QY experiments. 


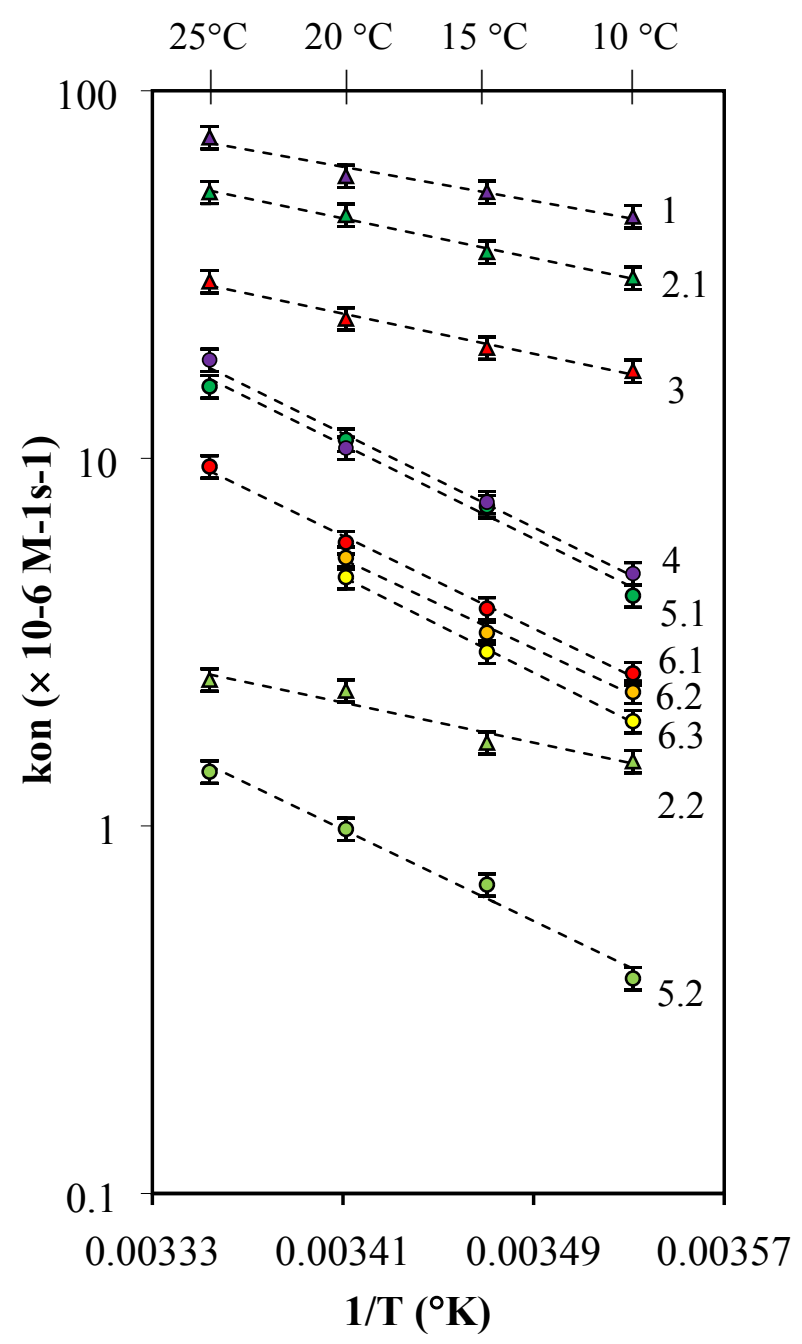

Figure 8

Figure 8. Arrhenius plot ( $\left.\ln \mathrm{k}_{\text {on }} \mathrm{Vs} 1 / \mathrm{T}\right)$ of the association rate constants plotted in semi-logarithm for clarity. Temperature dependence of the biotin association reaction at $\mathrm{pH} 8$ (unless otherwise specified) for: $1 \mathrm{SAV}-\mathrm{BF}$ (purple triangles); $2 \mathrm{SAV}$-biotin-DNA $\mathrm{ds}^{*} \mathrm{Fl}$ (green triangles): $2.1\left(\mathrm{k}_{\mathrm{on} 1}\right)$ and $2.2\left(\mathrm{k}_{\mathrm{on} 2}\right) ; 3 \mathrm{SAV}-\mathrm{BcO}$ (red triangles); $4 \mathrm{AV}-\mathrm{BFl}$ (purple circles); 5 AV-biotin-DNA ${ }_{\mathrm{ds}}{ }^{\mathrm{F}} \mathrm{Fl}$ (green circles): $5.1\left(\mathrm{k}_{\mathrm{on} 1}\right)$ and $5.2\left(\mathrm{k}_{\mathrm{on} 2}\right) ; 6 \mathrm{AV}-\mathrm{BcO}$ (red circles): 6.1 at $\mathrm{pH} \mathrm{8,6.2} \mathrm{at} \mathrm{pH} 9$ (orange circles), 6.3 at pH 10 (yellow circles). 

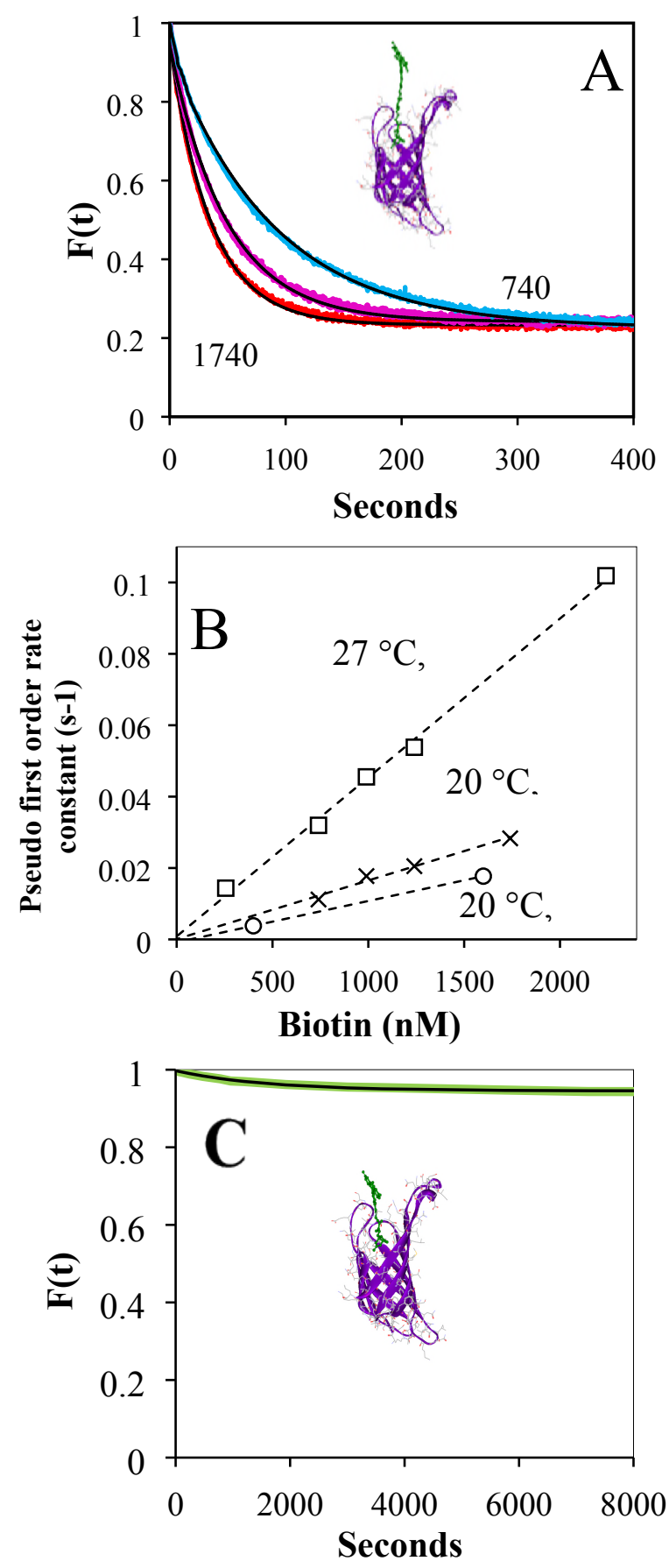

Figure 9

Figure 9. A) Concentration dependence of the displacement reaction of $\mathrm{SAV}-\mathrm{BcO}$ complex $\left(\mathrm{AB}_{1}\right.$ model) by unlabeled biotin at $20^{\circ} \mathrm{C}$. The concentration of challenging $\mathrm{B}_{7}$ was $740 \mathrm{nM}$ (blue), 1240 $\mathrm{nM}$ (pink) and $1740 \mathrm{nM}$ (red) after the remaining free binding sites were filled. The half-times were $56.6 \mathrm{~s}, 33.9 \mathrm{~s}$ and $24.2 \mathrm{~s}$, respectively; with a release amplitude of $79 \pm 1 \%$. B) Temperature dependence of the displacement reaction of $\mathrm{SAV}-\mathrm{BcO}$ by unlabeled $\mathrm{B}_{7}$ for the $\mathrm{AB}_{1}$ filling model (at $20^{\circ} \mathrm{C}$ and $27^{\circ} \mathrm{C}$ ) and for the $\mathrm{AB}_{4}$ model (at $20^{\circ} \mathrm{C}$ ). The corresponding $k^{\text {displacement }}$ off (calculated from the slope) were $1.64 \pm 0.4 \times 10^{5} \mathrm{M}^{-1} \mathrm{~s}^{-1}, 4.62 \pm 0.3 \times 10^{5} \mathrm{M}^{-1} \mathrm{~s}^{-1}$ and $1.20 \pm 0.3 \times 10^{5} \mathrm{M}^{-1} \mathrm{~s}^{-1}$, 
respective. C) Displacement reaction of unlabeled biotin and SAV-BFl complex ( $\mathrm{AB}_{1}$ filling model) at $30^{\circ} \mathrm{C}$. The concentration of challenging biotin was $1400 \mathrm{nM}$ which produced a release of only $5 \%$ of the bound probe. The green curves is the observed data and black curve is the fitted curve for which only $6.5 \%$ displacement was observed for SAV-BFl complex in contrast with 79 $\%$ in case of the complex formed with the longer linker BcO. 
bioRxiv preprint doi: https://doi.org/10.1101/410548; this version posted September 6, 2018. The copyright holder for this preprint (which was not certified by peer review) is the author/funder, who has granted bioRxiv a license to display the preprint in perpetuity. It is made available under aCC-BY 4.0 International license. 

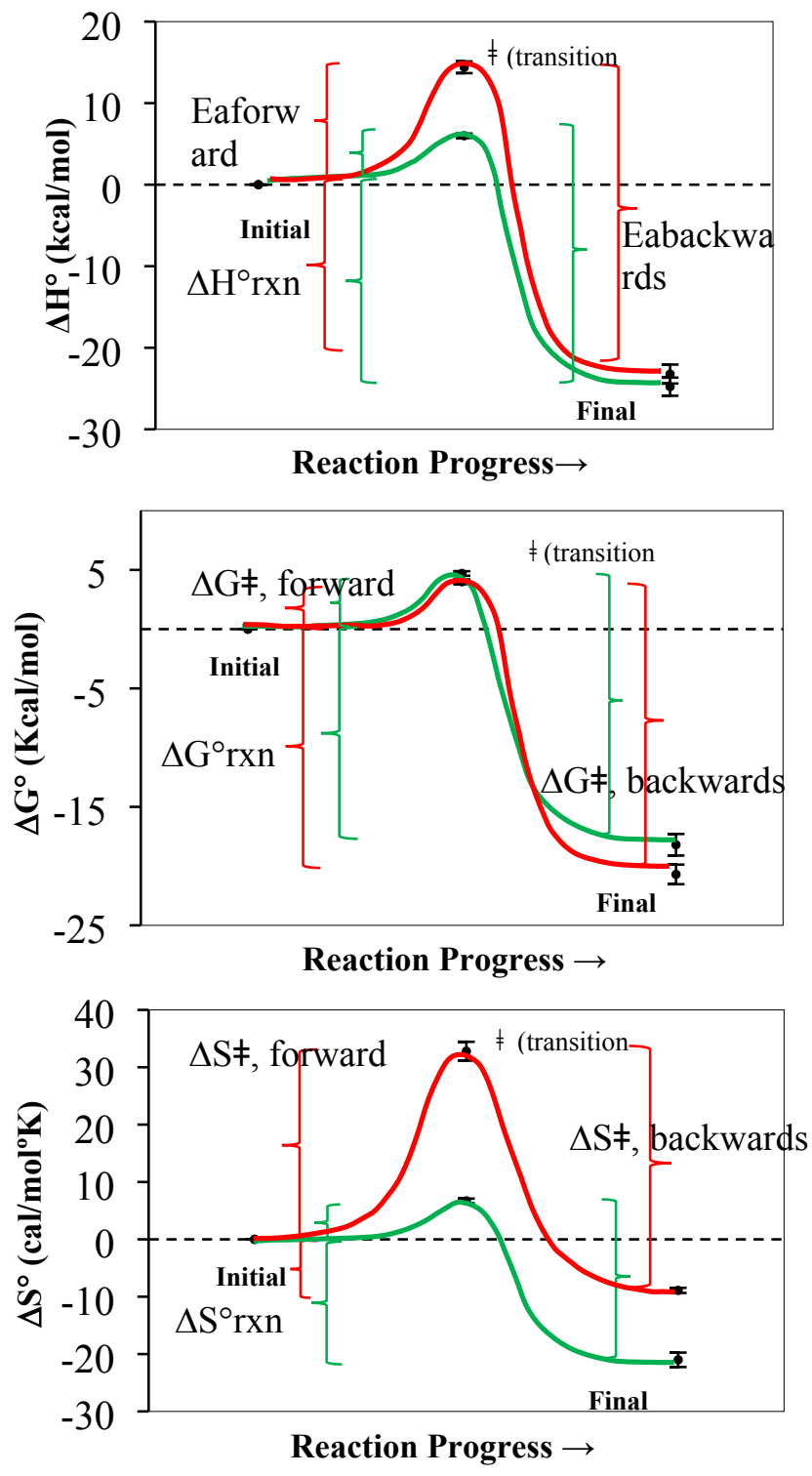

Figure 10

Figure 10. Thermodynamic cycle of the $\mathrm{B}_{7}$ binding to $\mathrm{AV}$ (red) and $\mathrm{SAV}$ (green) for one transition state and no intermediate: A) $\Delta \mathrm{H}^{\circ}{ }_{\mathrm{rxn}}$, B) $\Delta \mathrm{S}^{\circ}{ }_{\mathrm{rxn}}$ and C) $\Delta \mathrm{G}^{\circ}{ }_{\mathrm{rxn}}$ is the average of values found in multiple studies (Table 3). Arrhenius plots of the temperature dependent association and dissociation rate constants were used to calculate the $\mathrm{E}_{\mathrm{a}}$ forward and $\mathrm{E}_{\mathrm{a}}$ backwards, respectively. 

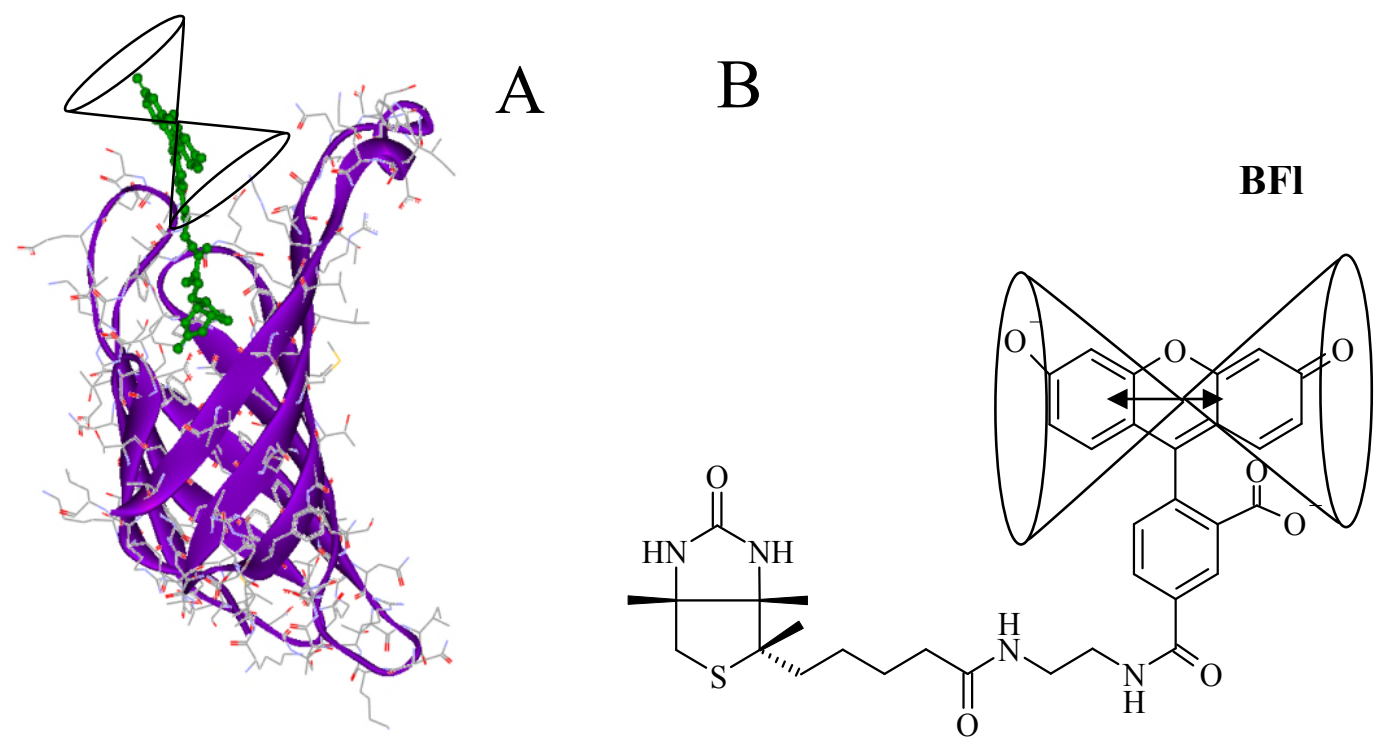

Figure 11

Figure 11. A) Pictorial representation of the AV-BFl complex for only one binding sites showing a relative high dye mobility with a half apical angle $88(\Omega)$ of $51^{\circ} \pm 2^{\circ}$ in contrast with the unrestricted mobility of the dye labeled $\mathrm{B}_{7}$ with $90^{\circ}$. The figures reflect rotational motion of the transition moment of the isoalloxanzine ring system within the cone B). The dye structure added using Accelrys DS visualizer $2.0{ }^{\circledR}$ to the AV-B crystal structure complex: 2AVI. ${ }^{29}$ 